\title{
The Impact of International Research Collaboration Network Evolution on Chinese Business School Research Quality
}

\author{
Wei Fang $(\mathbb{D}$, Sheng Dai, and Lulu Tang \\ School of Management, Northwestern Polytechnical University, Xi'an 710072, China \\ Correspondence should be addressed to Wei Fang; fwx1998@nwpu.edu.cn
}

Received 15 August 2019; Revised 21 November 2019; Accepted 29 November 2019; Published 8 January 2020

Academic Editor: José Manuel Galán

Copyright (c) 2020 Wei Fang et al. This is an open access article distributed under the Creative Commons Attribution License, which permits unrestricted use, distribution, and reproduction in any medium, provided the original work is properly cited.

\begin{abstract}
The University of Texas at Dallas has proposed 24 top journals (UTD24) covering all areas related to management. UTD24 are currently the most authoritative management journals. Institutions or research scholars who have published papers in these journals are considered to have a high academic level. This study uses the paper quality published by an institution in the UTD24 journals to indicate the research quality of this institution and takes the papers published by Chinese Business School in the UTD24 journals from 2000 to 2018 as the research object. By analyzing the staged evolution process and the research hotspot of international research collaboration network (IRC network) of Chinese Business School, this paper summarizes and analyzes the factors that influence the quality of papers published by Chinese Business School in UTD24 journals: degree centrality of an institution, betweenness centrality of an institution, the degree of attention of an institution, the degree of novelty of an institution, and the number of countries cooperating with the institution. This paper divides paper quality into two parts: the total number of papers and citations per paper of an institution. Among them, degree centrality and betweenness centrality of the institution have a significant positive impact on the total number of papers of the institution. The degree of attention and the number of countries cooperating with the institution have a significant positive impact on citations per paper, and the degree of novelty has a significant negative impact on citations per paper.
\end{abstract}

\section{Introduction}

In recent years, science and technology have developed rapidly, subject knowledge has also grown rapidly, and scientific research cooperation has gradually become the main form of scientific research [1]. For scientific research personnel, scientific research cooperation and communication can effectively improve the competitiveness of individual scientific research $[2,3]$. For the research team, by sharing information and resources, it will help to brainstorm ideas, bring into play the value of knowledge, achieve the maximum benefit of the team, and improve the level and quality of research. Bozeman et al. [4] considered collaborations aimed chiefly at expanding the base of knowledge (knowledge-focused collaborations) as well as ones focused on production of economic value and wealth. In short, through scientific research cooperation, it is of great significance to the cultivation of disciplinary compound talents and the leaping development of disciplines $[5,6]$. Coccia and
Bozeman [7] confronted analyses of the relative growth of international research collaboration in comparison with domestic collaboration only for fields of science by developing an allometric model of morphological changes in order to measure. Bozeman et al. [8] developed a provisional model of research collaboration effectiveness, deriving data from 60 US academic researchers, selected from a range of scientific and engineering disciplines as well as one social sciences discipline. Some scholars have explored the factors influencing research cooperation and have studied the influence of research collaborations $[9,10]$.

With the deepening of management discipline research and the continuous development of management practice, the degree of discipline specialization has gradually improved. In practice, a topic or project is often completed by a number of different researchers, and the journal papers are combined. It has become the most intuitive form of scientific research cooperation [11]. In a certain period of time, the number of papers and cooperation between authors and 
research institutes in the field of management disciplines also largely reflects the speed and quality of scientific research cooperation and academic exchanges within the disciplines [12]. The analysis of the phenomenon of management disciplines will undoubtedly help to better understand the development characteristics of management disciplines and understand the academic cooperation status and general characteristics of management disciplines [13].

In practice, some scholars have studied paper co-authored network, but the previous research is more limited by the analysis technology. Through simple bibliometrics and statistics on the author's volume of publications, the distribution of cooperation, and the rate of cooperation, some scholars have sorted out the cooperation in the field of research. However, such research is lacking in the deep cooperation relationship behind the co-authored phenomenon and in determining the status and role of individuals (authors or institutions) in the disciplinary cooperation network. Newman $[14,15]$ analyzed the structure, co-authorship networks, and patterns of scientific collaboration. The advancement of scientific research technology, especially network analysis technology, provides the possibility to explore large-scale cooperative networks within disciplines. This paper comprehensively uses the bibliometric analysis and social network analysis to study the literature cooperation status of Chinese Business School at top international journals of management disciplines. To some extent, it has a certain reference to how Chinese Business School can publish high-level papers. The research in this paper also has certain theoretical significance. While enriching the relevant literature research in this field, it also provides a new perspective for the management literature research. It provides a clear reference for Chinese scholars in future research hotspots, research directions, and international cooperation.

\section{Theoretical Framework}

Social networks are one of the most visual and effective tools for characterizing and measuring social relationships [16]. Social relations influence various social behaviors. How do we study the impact of these relationships on social behavior and the consequences? Social networks are undoubtedly the most effective tools for visualizing these relationships. As a collection of social actors and their mutual relationships [17], the important reason for introducing it into the field of management lies in the fact that management practice and theoretical research face many challenges in the new environment, and social network theory can provide a new analytical perspective for this kind of challenge [18]. Social networks play an important role on innovation management [19-21], knowledge management [22], the acquisition of intelligence information, and the research on diffusion mechanism of information and intelligence [23], Therefore, social networks have been widely used in the study of sociology and information science.

Social network analysis is based on the interaction between social actors, using points to represent social actors, and using the connections of points to represent a certain social relationship between actors in order to quantify these social relationships. In recent years, social networks have been widely used in academic research, especially the study of the relationship between various social entities, and have formed a unique research paradigm. For example, Liu and Guan used social network analysis to study the evolution of research cooperation networks [24]. Social network analysis has made significant contributions in the fields of sociology, social psychology, humanities, epidemiology, and management research [25]. In the field of management, social network analysis is widely used in the fields of knowledge management, entrepreneurship management, strategic management, innovation management, corporate governance, marketing management, human resource management, and organizational behavior in management, and the theoretical community pays more and more attention to its application in management $[26,27]$. Although there are many other quantitative methods to study cooperation in management, social network analysis is an effective method to quantify the influencing factors.

Bibliometric analysis is a kind of literature analysis tool that can objectively and quantitatively reveal the development of academic research $[28,29]$. It is mainly used in the fields of information science, library science, and archival science. Bibliometric analysis refers to the quantitative analysis of the research focus and future research direction of an academic field by quantitative analysis of the literature information of keywords, authors, journals, years, institutions, literature content, and citation information [30]. It Includes co-word analysis and cluster analysis. For subject areas with large sample sizes, co-word analysis can quickly grasp the research status and trend evolution of related disciplines, so it is widely used in the research of subject development trends [31, 32]. In the field of economic management, many scholars have used bibliometric analysis to describe the research status and progress in this field and have found that the evolution of a research field is driven by few disciplines [33]. Heischmidt and Gordon [34] have measured the ranking of marketing academic journals, González et al. [35] analyzed the main research methods of learning, Silva and Teixeira [36] have analyzed the research path of econometric evolution economics, etc. Since the network has become the main form of innovation and diffusion, it has been found in the existing literature that most of the research related to knowledge diffusion is based on the network. In the research network, since explicit knowledge and tacit knowledge usually exist in the form of knowledge carriers, that is, papers, the process of knowledge diffusion usually traces the index information of papers. In the network environment, a kind of related research on knowledge diffusion is the use of network methods to analyze the characteristics of knowledge diffusion. Such research reveals the diffusion characteristics of subject structure and scientific knowledge through the analysis of the characteristics of citation networks.

\section{Research Samples and Data}

3.1. Sample Selection. Choosing a cluster of journals that cover and represent the broad areas of knowledge of management as a source of data is critical to ensuring the 
rationality and reliability of subsequent analytical conclusions. The ranking of journals in the management field has also attracted the attention of a large number of scholars. Although scholars [37, 38] have adopted different methods to select and rank management academic journals, they have obtained different results, but the results are highly correlated. Although the main top journals in the field have differences in order, they are basically included in the selection range, indicating that everyone's approval for top journals is relatively consistent.

The Naveen Jindal School of Management at the University of Texas at Dallas has a research on the ranking of global business schools named "UTD Top 100 Business Schools in the World" in order to compare different business schools' quality and quantity of papers published in related fields. Its research has a greater influence. UTD Business School's 24 journals (UTD24) have also become one of the most important standards for business measurement in terms of academic strength. The 24 journals are recognized worldwide as leading international business journals. At the same time, through supplemental confirmation, compared with JCR, these 24 journals which have higher impact factors, covering a comprehensive range of management related fields (including Accounting, Finance, Information management, Marketing, Management science, Operations research, Business administration/management, etc), are the collection of management journals studied in this paper. Taking the papers of these journals published by Chinese Business School as the research samples and analyzing them, the conclusions can be used to give reference to the other Chinese Business School that want to improve their scientific research strength and paper quality. This paper collected all the papers published by Chinese Business School in UTD24 from 2000 to 2018 through Web of Science. The search method is to separately search for the name of the journal and add the search period to the search results of each journal: 2000 to 2018 and the nationality of the authors' institutions each journal: People's Republic of China. Disciplines of these 24 journals, the journal title, the journal impact factors, and the number of papers published by Chinese Business School in these journals from 2000 to 2018 are shown in Table 1.

3.2. Statistical Description. We have drawn Figure 1 based on the papers published by Chinese Business School on UTD24 from 2000 to 2018. The data in Figure 1 does not include paper whose authors are from same institution. As can be seen from Figure 1, the number of papers published by Chinese Business School on UTD24 is generally increasing year by year. The trend line is $y=0.4614 x^{2}+2.357 x+29.442$, and its $R^{2}$ value is 0.9628 , which is close to 1 , indicating that it has higher reliability. From the data results, we can observe certain phase characteristics of the number of publications: 2000-2006 (the number is small and the trend is relatively stable), 2007-2013 (the number grows with a certain trend), and 2014-2018 (the quantity is basically maintained at a high level of fluctuation). Similarly, according to Dehdarirad's data processing method [39], we can also divide the data into three phases: 2000-2009, 2010-2014, and 2015-2018. Therefore, combined with the data above, we conceive whether the IRC network based on sample data has a phased evolutionary feature.

\section{Staged Evolution Model of IRC Network of Chinese Business School}

4.1. Statistics of IRC Network. As an IRC network with multisubject interaction, the co-authoring network can be used to describe IRC network. Through Web of Science, the papers published by Chinese scholars in the UTD24 journals from 2000 to 2018 were retrieved and the authors' institutions were extracted. This section deletes papers whose authors are from the same institution from the sample and uses the other papers in the sample to build the IRC network. If a paper has multiple authors from different institutions, then the institutions of these authors are connected two by two. Author's institutions of each paper are the nodes of the network and relationship between the institutions through the co-authoring of paper is the edge of the network. It can also use the structural indicators of social network analysis fields such as structural hole, centrality, average distance, and clustering coefficient to characterize the spatial state of network.

Structural holes refer to the direct connection between certain individuals in the network, but no direct contact or discontinuity with other individuals [40-42]. The measurement method for structural holes usually adopts the effective size in the Bert structure hole indicator, which is equal to the nonredundant factor in the network and is the ability of the innovation subject to use structural holes in the individual network. The effective size of the international cooperative network node $j$ of China Business School is

$$
S_{i}=\sum_{j} 1-\sum_{q} p_{i q} m_{i q}, \quad q \neq i, j,
$$

where $j$ denotes all collaborators connected to $i, q$ is another contact except $i$ and $j$; $p_{i q}$ is the proportion of the relationship of $q$ in all relationships of node $i$; and $m_{i q}$ is the marginal strength of relationship of $j$ to $q$ and takes a value of 1 or 0 . Effective scale $S_{i}$ measures the ability of node $i$ to obtain information opportunities in the network. The larger $S_{i}$, the larger the structural hole of network node $i$.

Therefore, the total effective size (weighted average) of network is

$$
S=\sum_{i}\left(\frac{S_{i}^{2}}{\sum S_{i}}\right) .
$$

The structural hole in the process of cooperative innovation is crucial and is the key to the full integration of resources $[43,44]$. Therefore, the larger the total effective size of the network, the more the structural holes are in the network and the better the ability of integrating resources the network has.

The centrality is also called the betweenness centrality, which is mainly used to measure the degree of control of 
TABLE 1: Journal name and impact factor of UTD24 and number of papers published by Chinese busines schools from $2000-2018$.

\begin{tabular}{|c|c|c|c|}
\hline Discipline & Journal title & Journal impact factor & Number of papers \\
\hline \multirow{3}{*}{ Accounting } & Journal of Accounting Research & 4.542 & 36 \\
\hline & Journal of Accounting \& Economics & 3.282 & 57 \\
\hline & Accounting Review & 2.245 & 87 \\
\hline \multirow{3}{*}{ Finance } & Journal of Finance & 5.397 & 56 \\
\hline & Journal of Financial Economics & 5.162 & 142 \\
\hline & Review of Financial Studies & 4.270 & 88 \\
\hline \multirow{3}{*}{ Information management } & MIS Quarterly & 5.430 & 69 \\
\hline & Information Systems Research & 2.301 & 89 \\
\hline & INFORMS Journal on Computing & 1.392 & 53 \\
\hline \multirow{4}{*}{ Marketing } & Journal of Marketing & 7.338 & 45 \\
\hline & Journal of Marketing Research & 3.854 & 84 \\
\hline & Journal of Consumer Research & 3.535 & 97 \\
\hline & Marketing Science & 2.794 & 61 \\
\hline \multirow{5}{*}{$\begin{array}{l}\text { Management science/operations } \\
\text { research }\end{array}$} & Journal of Operations Management & 4.899 & 49 \\
\hline & Management Science & 3.544 & 221 \\
\hline & Operations Research & 2.263 & 194 \\
\hline & $\begin{array}{c}\text { MeSOM-Manufacturing \& Service Operations } \\
\text { Management }\end{array}$ & 1.795 & 69 \\
\hline & Production and Operations Management & 1.772 & 200 \\
\hline \multirow{6}{*}{ Business administration/management } & Academy of Management Review & 8.855 & 16 \\
\hline & Academy of Management Journal & 6.700 & 115 \\
\hline & Journal of International Business Studies & 6.198 & 162 \\
\hline & Administrative Science Quarterly & 5.878 & 13 \\
\hline & Strategic Management Journal & 5.482 & 111 \\
\hline & Organization Science & 3.027 & 45 \\
\hline
\end{tabular}

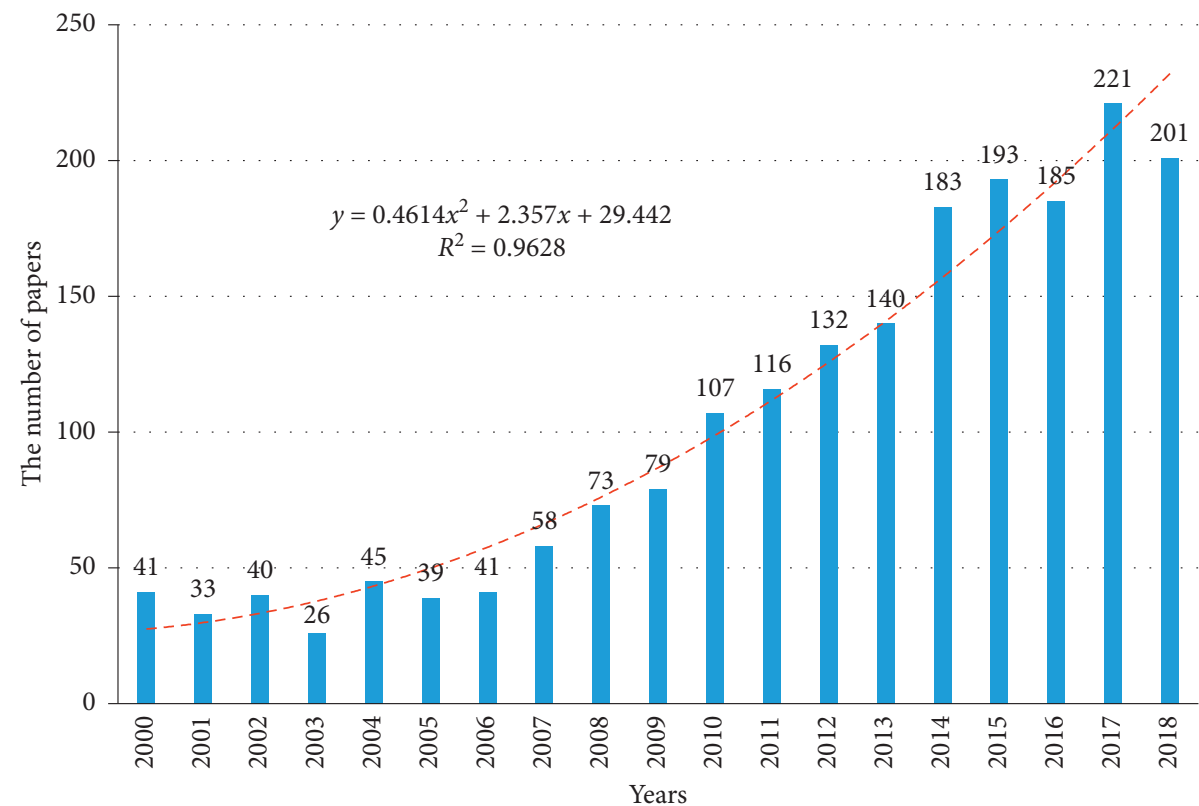

FIgUre 1: Number of papers published by Chinese business school on UTD24 from 2000-2018.

resources by network nodes. Here, we use betweenness centralization of the total network to calculate.

Set the network $G=(V, E), V$ is the point set, $E$ is the edge set, $E \subseteq V \times V, e=(u, v) \in E$, and $u$ and $v$ are the head and tail of the edge $e$. $(s, t)$ - path: means the way from point $s$ to point $t$. $(s, t)$ - pathlength: represents the number of lines included in the path. $\operatorname{dist}(s, t)=\min \{(s, t)-$ pathlength $\}$ is the shortest path length. $\sigma(s, t)=\operatorname{sum}(\operatorname{dist}(s, t))$ is the number of the shortest path length; if $s=t$, then $\sigma(s, t)=1 ; \sigma(s, t \mid v)$ represents the shortest the number of $(s, t)-$ path through point $v$; if $v \in(s, t)$, let $\sigma(s, t \mid v)=0$.

Thus, the absolute betweenness centrality $C_{B}(V)$ of point $v \in V$ is

$$
C_{B}(V)=\sum_{s, t \in V} \frac{\sigma(s, t \mid v)}{\sigma(s, t)}
$$


where $C_{B}(V) \in[0,1]$; the larger the $\mathrm{CB}(\mathrm{V})$ is, the more the resources are controlled by point $\mathrm{v}$. Based on the above results, the betweenness centrality that can express the overall intermediation strength of the network can be calculated by using the following betweenness centralization indicator:

$$
C_{B}=\frac{\sum_{v}\left(C_{B \max }(v)-C_{B}(v)\right)}{n^{3}-4 n^{2}+5 n-2},
$$

where $C_{B \max }(v)$ is the maximum value of the absolute betweenness centrality in the network. The greater the central $C_{B}$ of the overall cooperative network of the Chinese business school, the stronger the intermediation of the network and the more obvious the role of the middleman.

The average distance, also known as the geodesic path, refers to the mean path length of connecting any two nodes which have the fewest lines in the network. The network average distance $(D)$ reflects the strength of the relationship between the various agents in the network:

$$
D=\frac{\operatorname{sum}\left(d_{e_{i j}}\right)}{\operatorname{sum}(E)}, \quad i \in V_{1}, j \in V_{2},
$$

where $\quad d_{e_{i j}}=\operatorname{dist}(s, t)=\min \{(s, t)-$ pathlength $\} \quad$ is the shortest path length between nodes $i$ and $j$. The shorter the margin $\left(d_{e_{i j}}\right)$ between any two nodes, the closer the relationship between the two nodes [45]. Therefore, the smaller the average distance $D$ of the network, the better the rapid transmission of network information and resources, thereby improving the innovation efficiency of the network.

4.2. Method of IRC Network's Stage Division. As a complex system, the spatial evolution of the network is inevitably affected by the orderliness of the system. While the spatial status indicator of network can effectively express the static characteristics of the network as a whole, it is difficult to accurately measure the self-organization (ordered) of the network.

According to the formula of the entropy proposed by Shannon in information theory: $H=-\sum p_{i} \log p_{i}$, it can be known that the determination of the discrete probability $p_{i}$ of events is the key to measuring the orderly evolution of the cooperative network. This paper considers that "entropy" can reflect the order of the overall evolution of the network, but it needs the intermediate variable (event) of the spatial status indicator of network to calculate the entropy value. Therefore, the following spatial indicators of network are constructed:

$$
\begin{aligned}
& H_{j}=-p_{j} \log p_{j}, \\
& p_{j}=\sum\left(\frac{p_{i j}^{2}}{\sum_{j} p_{i j}}\right),
\end{aligned}
$$

where $p_{i j}=Q_{i j} / \sum Q_{i j}, Q_{i j}$ indicates the observation value of the $j$ th period of the ith spatial status indicator of network, and $i=1,2$ represents the structural hole $S$ and the betweenness centralization $C$, respectively. The average distance $D(i=3)$ is inversely related to the orderly evolution of the network, so $p_{i j}=1-Q_{i j} / \sum Q_{i j}$. Since the evolution of the $j$ th cooperation network has only one state $p_{j}$, its entropy value can be calculated in a single calculation. In summary, as the value of $j$ increases, the entropy value of network evolution will show a continuous trend, which is conducive to reveal the orderly evolution of network systems.

The spatial evolution measure vector of the international cooperation network of China Business School is $H=\left(H_{1}, H_{2}, \ldots, H_{n}\right)$, and $H_{j}$ is the entropy value of the network space evolution calculated in the $j$ th stage. The specific network evolution phase is divided as follows.

Transform the element $H_{j}$ in the matrix $H$ into $Z_{j}$ to obtain the normalized matrix $Z=\left(Z_{1}, Z_{2}, \ldots, Z_{n}\right)$.

$$
Z_{j}=\frac{\left(H_{j}-\min \left\{H_{i}\right\}\right)}{\left(\max \left\{H_{i}\right\}-\min \left\{H_{i}\right\}\right)}, \quad i=1,2, \ldots, n,
$$

where $i$ is arranged in the order of the matrix $H$ (small to large).

Let the normalized matrix distribution in $[a, b]$ for a certain time period be $\left(Z_{a}, Z_{a+1}, \ldots\right)\left(Z_{b}\right)$, and the difference between the internal entropy values of the segment is

$$
\begin{aligned}
d_{a b} & =\sum_{a=a}^{b}\left[Z_{a}-\bar{Z}(a, b)\right]^{2}, \\
\bar{Z}(a, b) & =\frac{\left(\sum_{a=a}^{b} Z_{a}\right)}{(b-a+1)} .
\end{aligned}
$$

Then, when the matrix $Z$ is divided into $k$ segments, the variation matrix is obtained $D=\left(D_{1}, D_{2}, \ldots, D_{k}\right)$, where $D_{i}=\left[d_{a b}\right], i=1,2, \ldots, k$.

The basic idea of optimal segmentation: find a set of segmentation points so that the internal variation $S_{1}$ of each time period is minimum value and the variation $S_{2}$ between the time periods is the maximum value. At the same time, the study found that for a given observations, the total variation $S=S_{1}+S_{2}$ is a fixed amount, and it can be known that if the variation $S_{1}$ within the group is the smallest, the variation $S_{2}$ between groups must be the largest. Therefore, when the matrix $Z$ is divided into $k$ segments, only $k-1$ segmentation points can be found according to the principle of the smallest variation within the group, and the optimal segmentation can be realized. The stage of the evolution of the international cooperation network of Chinese Business School is divided accordingly.

Let $P(n, k)$ denote the division of $n$ consecutive entropy values in matrix $Z$ into $k$ segments. When $k=2$, the optimal segmentation point can be obtained by the objective function:

$$
e[P(n, 2)]=\min _{2 \leq j \leq n}\{D(1, j-1)+D(j, n)\},
$$

and when $k=3$, the optimal segmentation point can be obtained by the objective function: 


$$
\begin{aligned}
e[P(n, 3)]= & \min _{2 \leq i \leq j, 3 \leq j \leq n}\{D(1, i-1)+D(i, j-1) \\
& +D(j, n)\}=\min _{3 \leq j \leq n}\{e[P(j-1,2)]+D(j, n)\} .
\end{aligned}
$$

By analogy, the general objective function formula divided into $k$ segments in the network evolution phase can be obtained as

$$
e[P(n, k)]=\min _{k \leq j \leq n}\{e[P(j-1, k-1)]+D(j, n)\} .
$$

Using the retrograde method to solve this formula, we can get the optimal segmentation point of $k-1$ stage division.

Since the optimal segmentation method does not give the exact number of segments, the ratio method can be used to determine the optimal $k$ value:

$$
a=\frac{e[P(n, k)]}{e[P(n, k+1)]} .
$$

After calculation, the more the stages of division, the smaller the value of the function, so we take the value of $a$ closest to one. The closer the value of a is to 1 , the closer the function value of the $k+1$ stage is to the function value of the $\mathrm{k}$ stage and there is no need to divide.

4.3. Data Result of IRC Network's Stage Division. Construct a 19-year international cooperation network, respectively, through the method described in Section 4.1 and use the formulas (2), (4), and (5) to calculate effective size $(S)$, betweenness centralization $(C)$, and average distance $(D)$ of 19 networks by the software UCINET. After determining the above indicators, we can further derive the event probabilities $p_{1}, p_{2}$, and $p_{3}$ and the probability $p$ after weighting and use formula (6) to calculate the weighted entropy $H_{j}$ of international cooperation network of Chinese Business School. These indicators are shown in Table 2 .

Then, we use the software MATLAB to normalize the data of weighted entropy $H_{j}$ to matrix $Z$ and calculate the variation matrix of $H$ by equation (8). According to this, the variation minimum value of the cooperative network under different segment numbers $k$ can be determined. This article has only 19 years of data, so we have decided to divide the number of stages by no more than 5 segments. After calculation, $a_{23}=1.38, a_{34}=1.28$, and $a_{45}=1.80$. The value of $a_{34}$ is the smallest and closest to 1 , which means the value of function divided into three stages is similar to the value of function divided into four stages, and there is no need to continue dividing, so it should be divided into three segments. The specific results are shown in Table 3.

Therefore, from the above data, we can divide the evolution of the international cooperation network of Chinese Business School into the following three stages: 2000-2008, 2009-2013, and 2014-2018.
TABLE 2: Model data results.

\begin{tabular}{lccccc}
\hline Years & $p_{1}$ & $p_{2}$ & $p_{3}$ & $p$ & $H_{j}$ \\
\hline 2000 & 0.056 & 0.053 & 0.964 & 0.058 & 0.239 \\
2001 & 0.094 & 0.062 & 0.966 & 0.065 & 0.255 \\
2002 & 0.072 & 0.047 & 0.961 & 0.059 & 0.241 \\
2003 & 0.037 & 0.048 & 0.976 & 0.057 & 0.235 \\
2004 & 0.088 & 0.048 & 0.946 & 0.060 & 0.243 \\
2005 & 0.096 & 0.048 & 0.953 & 0.062 & 0.249 \\
2006 & 0.063 & 0.054 & 0.959 & 0.057 & 0.237 \\
2007 & 0.056 & 0.057 & 0.960 & 0.057 & 0.236 \\
2008 & 0.069 & 0.052 & 0.948 & 0.058 & 0.238 \\
2009 & 0.049 & 0.056 & 0.949 & 0.055 & 0.230 \\
2010 & 0.042 & 0.054 & 0.948 & 0.055 & 0.230 \\
2011 & 0.036 & 0.055 & 0.948 & 0.054 & 0.228 \\
2012 & 0.048 & 0.054 & 0.936 & 0.054 & 0.227 \\
2013 & 0.039 & 0.054 & 0.941 & 0.054 & 0.226 \\
2014 & 0.039 & 0.052 & 0.929 & 0.052 & 0.223 \\
2015 & 0.025 & 0.054 & 0.932 & 0.052 & 0.221 \\
2016 & 0.036 & 0.052 & 0.923 & 0.051 & 0.220 \\
2017 & 0.023 & 0.054 & 0.926 & 0.051 & 0.219 \\
2018 & 0.024 & 0.052 & 0.930 & 0.051 & 0.219 \\
\hline
\end{tabular}

\section{Social Network Analysis of Staged IRC Network of Chinese Business School}

5.1. Overall Level Indicators of the IRC Network. According to the above staged evolution model and based on time as the standard, the evolution of the IRC network of Chinese Business School is divided into three stages: 2000-2008, 2009-2013, and 2014-2018. This paper analyzes the cooperation relationship between these three stages of the IRC network of Chinese Business School from the overall indicators of the network and the node-level indicators of the network. The former is mainly to analyze the overall characteristics of the IRC network, and the latter is mainly to further analyze from the individual level of the nodes in the network so as to try to explain the difference of the node level due to the heterogeneity of the individual. This paper uses the number of nodes, the number of edges, the density, the average degree, the average path length, the diameter, and the average clustering coefficient of the network to measure the overall characteristics of the cooperative network. The three centrality indicators of degree centrality, betweenness centrality, and closeness centrality are used to measure the evolution characteristics of node level in the network. This study regards author's institutions of each paper as the nodes of the network. This section deletes papers whose authors are from the same institution from the sample and uses other papers to build the IRC network. If a paper was written by multiple authors from different institutions, then the institutions of these authors are connected to one another. This paper uses this method above to build the IRC network of three stages, respectively. Network density measures the compactness of the network [46]. According to Table 4, we can see that the network density of the three stages will increase with the increase of the degree of the removed nodes and the connected components of the 
TABLE 3: Results of network segmentation.

\begin{tabular}{lccc}
\hline Value of $k$ & Number of division points & Value of $a$ & Optimal division point \\
\hline 3 & 2 & 1.28 & $9(2008), 14(2013)$ \\
\hline
\end{tabular}

TABle 4: The change of network density and number of connected components.

\begin{tabular}{|c|c|c|c|c|c|c|c|c|c|}
\hline \multirow{2}{*}{ Indicators } & \multicolumn{3}{|c|}{$2000-2008$} & \multicolumn{3}{|c|}{$2009-2013$} & \multicolumn{3}{|c|}{$2014-2018$} \\
\hline & $(1)$ & $(2)$ & (3) & $(1)$ & $(2)$ & (3) & $(1)$ & $(2)$ & $(3)$ \\
\hline Network density & 0.023 & 0.033 & 0.053 & 0.022 & 0.026 & 0.039 & 0.023 & 0.026 & 0.037 \\
\hline Number of connected components & 2 & 1 & 1 & 2 & 1 & 1 & 4 & 3 & 1 \\
\hline
\end{tabular}

Note. (1) Original network. (2) Remove the nodes which degree is one in the network. (3) Remove the nodes which degree is less than or equal to two in the network.

network will become smaller as the degree of the removed nodes increases. The change of these two indicators indicates that a certain number of nodes in the three phases of the network is isolated which means most nodes in the network only cooperate once. The degree of node is less than or equal to two, indicating that these institutions have fewer cooperation objects and cooperative outputs. After removing these nodes, the network is all connected. After that, we regarded the colleges and other institutions as nodes of networks and used the software Gephi to map the network evolution topology diagrams of these three stages as shown in Figure 2. In order to better present the process of network evolution, these network topology diagrams remove nodes whose degrees are less than two or equal to two. The node represents the institution to which the author of the published paper belongs. The size of the node in the figure indicates the value of the node degree. The more nodes there are connected, the larger the node is and the deeper the color is. The edges between the nodes indicate the cooperative relationship. The more cooperation between the two nodes, the deeper the color.

At the same time, we used software Gephi to calculate some of the network measurement indicators used in this paper, and the networks have removed the nodes whose degree is less than or equal to two. Complete indicator data are shown in Table 5. The number of nodes represents the number of institutions in a network. The more the nodes in a network, the larger the network size. In this paper, the number of network nodes in the three stages is 145,242 , and 349 , and the number of nodes is gradually increasing. The increasing number of nodes indicates that more and more business schools, research institutions, and related enterprises have joined the cooperation network to jointly complete related projects and have certain output results. The number of edges of the network indicates the number of co-authored paper relationships between institutions. The number of network edges in the three phases is 549,1146 , and 2226, which means collaboration between institutions is becoming more frequent, and a paper may have more institutions involved. The density of network is the ratio of the number of partnerships that exist in the network to the number of possible theoretical relationships. In this paper, the density of the network generally declines due to the fact that the number of possible theoretical relationships caused by the entry of new institutions is much larger than the number of actual relationships of the cooperation, indicating that the compactness of each node in the network is still gradually reduced and there is still a lot of room for improvement. The average degree of nodes gradually increases in three stages, indicating that the number of partners in a single institution become more and more. As the average degree increases, the cooperative network will show better synchronization capabilities, the cooperation rate will be significantly improved, and the scope of cooperation will be significantly expanded. The network diameter and the average path length generally show an upward trend, which indicates that the effectiveness of the network information transmission by a large number of new nodes joining in the network has been reduced to some extent, and the distance between the nodes has become far. The average clustering coefficient reflects the aggregation of the entire network. The larger the average clustering coefficient, the better the aggregation of the network. The aforementioned indicators of the whole network indicate that the scale of the network is increasing, and there are still many institutions joining in the network. The cooperation relationship between the nodes in the network is gradually increasing, but the information transmission efficiency inside the network is still at a low level; the aggregation of the network is still weak, and there is still much room for improvement.

5.2. Individual Indicators of IRC Network. In order to better analyze the status of the institutions in the international cooperation network of Chinese Business School, this part starts from the node level and adopts each node for centrality analysis. In social network analysis, the following three indicators are generally used to measure the influence of actors in the network, namely, degree centrality, betweenness centrality, and closeness centrality. These central indicators reflect the different locations of institutions in the co-authored network. The more direct contacts a node has, the more central the node is in the network; on the contrary, those who have less direct contact are marginal in the network. In this paper, degree centrality refers to the number of direct cooperation between an institution and other institutions in a co-network. It is equal to the scale of an institution's self-network, and the higher the degree of 


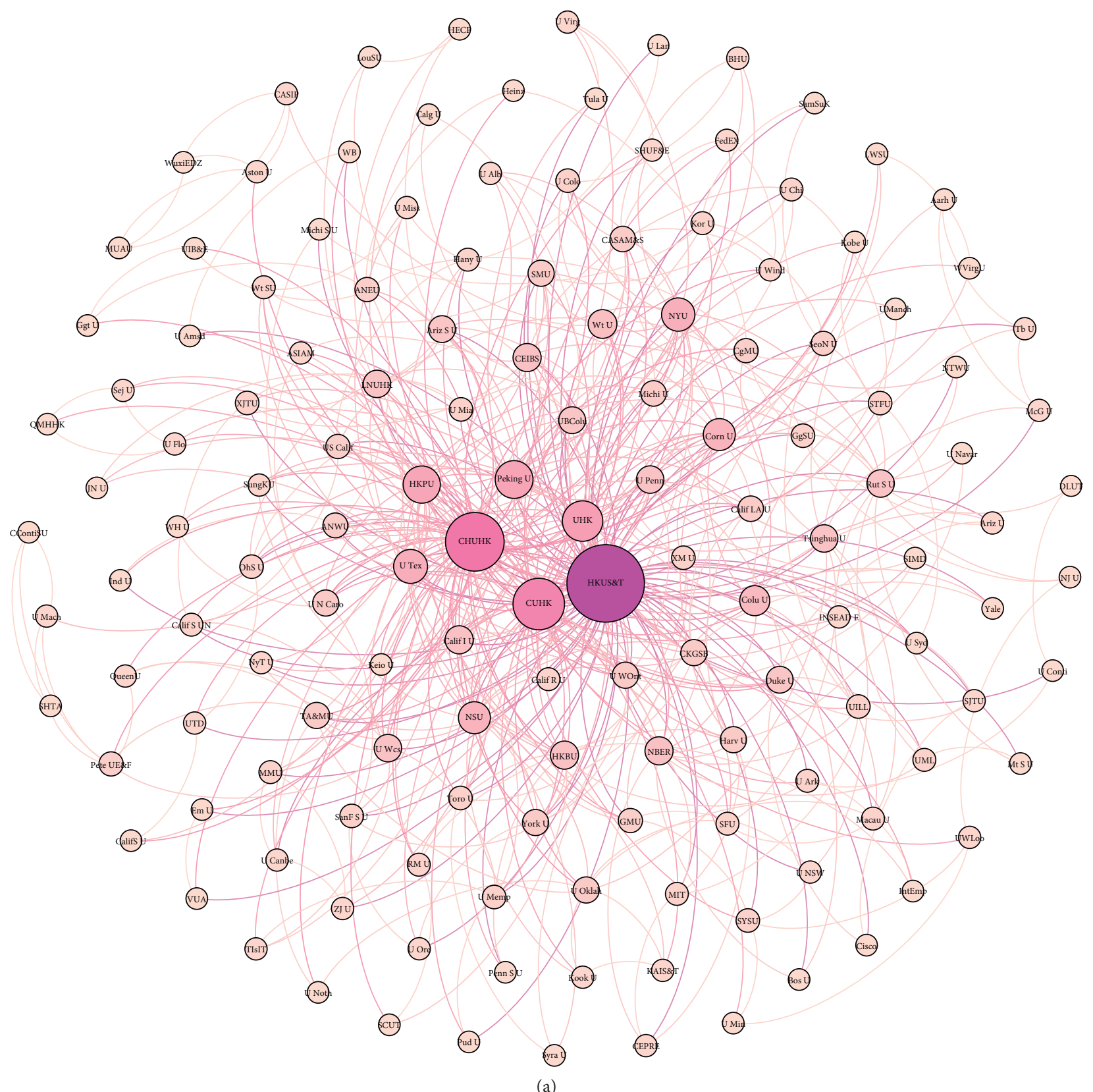

(a)

Figure 2: Continued. 


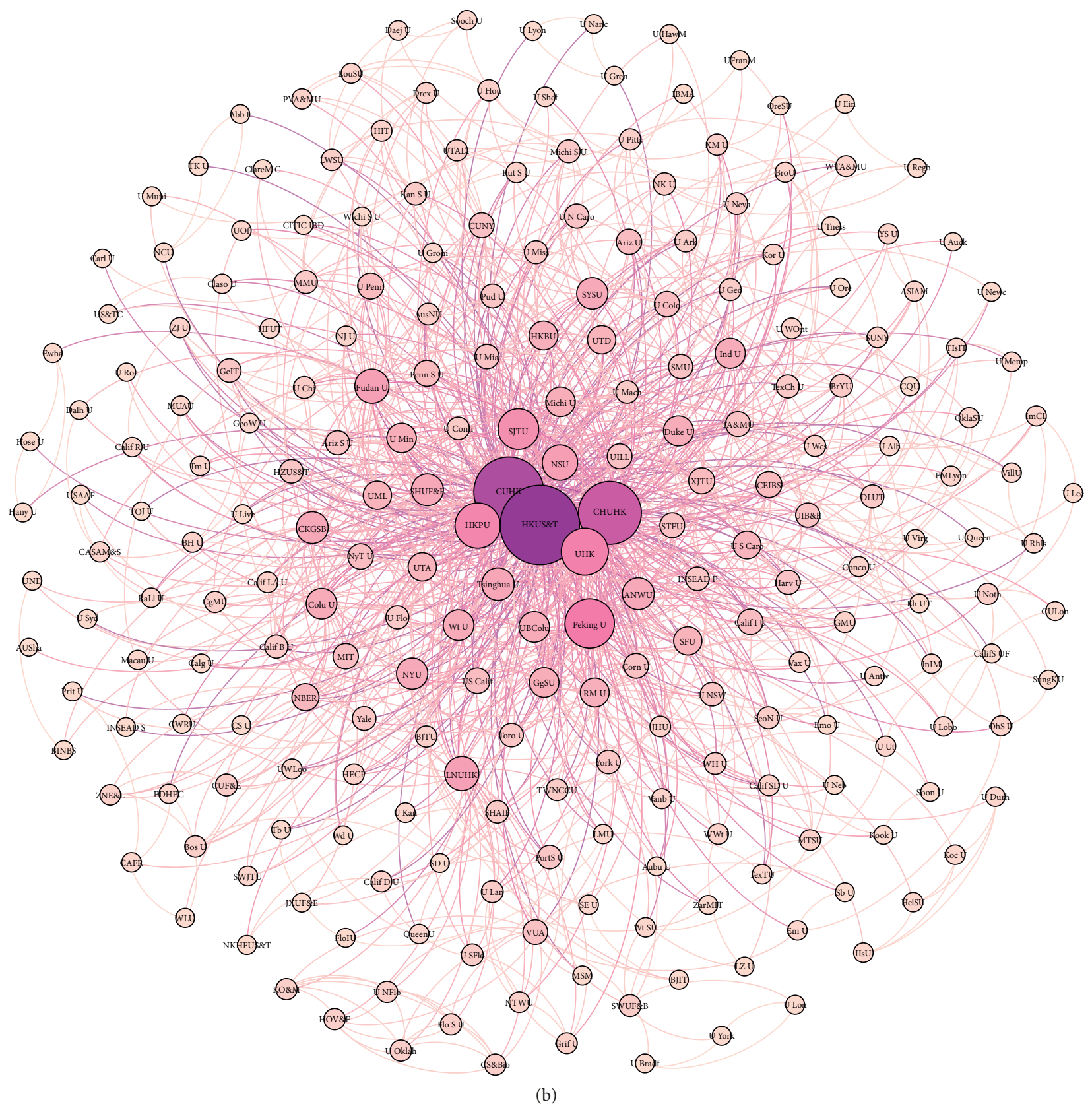

Figure 2: Continued. 


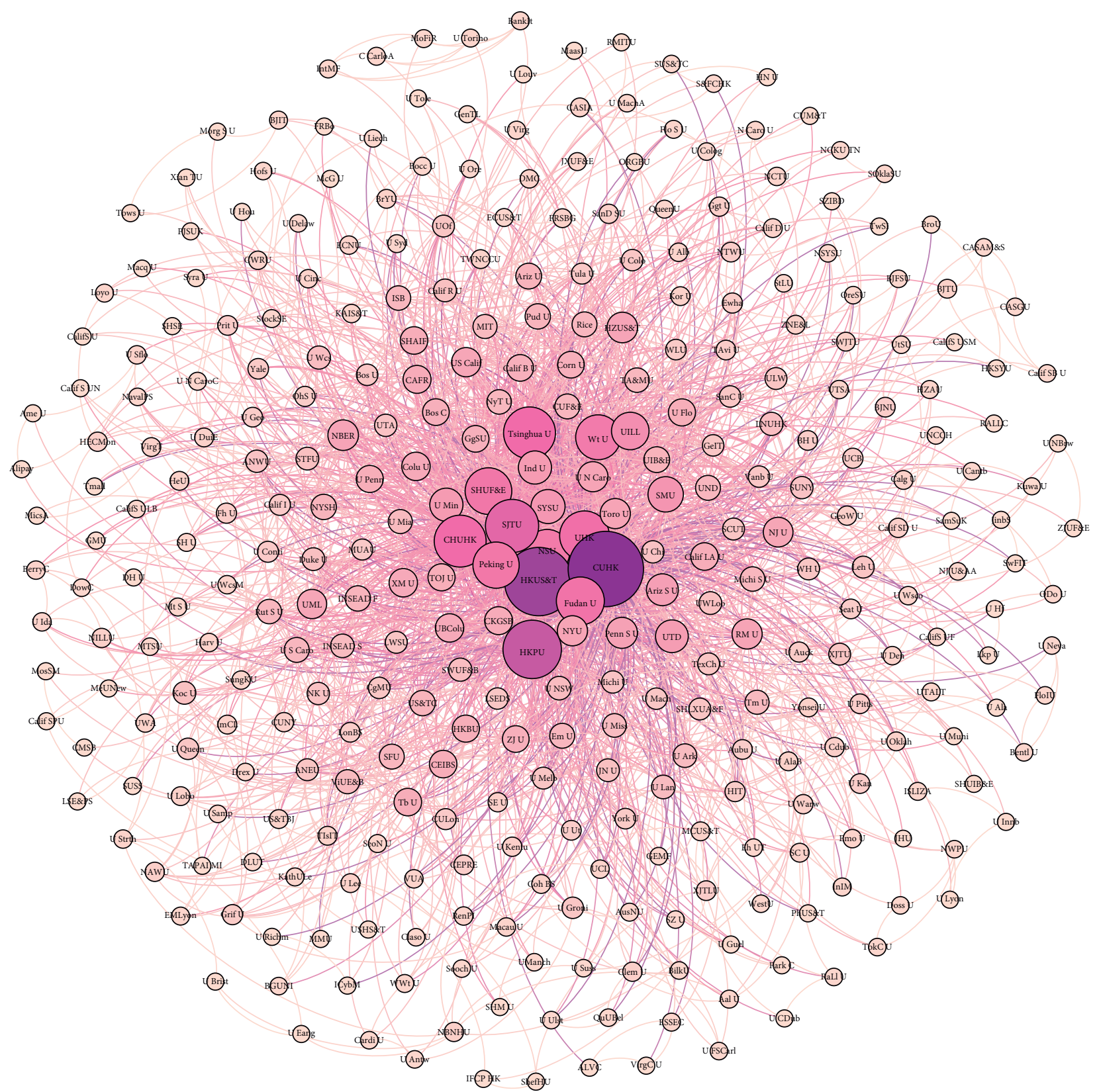

(c)

Figure 2: Three stages of international cooperation network evolution of Chinese business school from 2000-2018. (a) 2000-2008. (b) 2009-2013. (c) 2014-2018.

TABLE 5: Changes of network indicators in three phases.

\begin{tabular}{lccc}
\hline Indicators & $2000-2008$ & $2009-2013$ & $2014-2018$ \\
\hline Number of nodes & 145 & 242 & 349 \\
Number of edges & 549 & 1146 & 2226 \\
Density & 0.053 & 0.039 & 0.037 \\
Average degree & 7.572 & 9.471 & 12.756 \\
Average path length & 2.368 & 2.529 & 2.523 \\
Diameter & 5 & 5 & 6 \\
Average clustering coefficient & 0.666 & 0.641 & 0.619 \\
\hline
\end{tabular}


centrality, the greater the influence of the institution in the co-authored network. The networks in this article are all undirected, so the formula for calculating the degree centrality is as follows:

$$
C_{D}\left(n_{i}\right)=d\left(n_{i}\right)
$$

where $d\left(n_{i}\right)$ represents the sum of the institutions who have a direct association with a institution $i$. These linkages are mainly formed by co-publishing one or more academic papers.

Betweenness centrality indicators are used to measure the degree to which a node in a network controls resource. As a communication medium for two or more small groups, nodes with high betweenness centrality tend to gain information advantages. The greater the betweenness centrality of a node, the more likely it is that the node is at the core of the network and controls the communication between many other nodes. In a co-authored network, if an institution is on the shortest path of many other institutions, the institution can be considered to have a higher betweenness centrality because it acts as a bridge between the various nodes. The betweenness centrality is defined as shown in the following formula:

$$
C_{B}\left(n_{i}\right)=\sum_{j, k \neq i} \frac{g_{j i k}}{g_{j k}},
$$

where $g_{j i k}$ is the number of shortest paths through $i$ between node $j$ and node $k$ and $g_{j k}$ is the number of all shortest paths between node $j$ and node $k$. According to the definition, it can be seen that the betweenness centrality of the node is affected by the total number of nodes in the network. In order to eliminate this effect, the betweenness centrality of nodes in different networks can be compared with each other, and the relative betweenness centrality is defined as

$$
C_{B}^{\prime}\left(n_{i}\right)=\frac{2 C_{B}\left(n_{i}\right)}{n^{2}-3 n-2}
$$

The value of relative betweenness centrality is between $[0,1]$, so it can be used to compare the betweenness centrality of nodes in different networks.

Closeness centrality reflects how easy it is for a node to reach other nodes through the network. The closer a node is to other nodes, the easier it is to pass information. Actors with higher closeness centrality can pass information and transmit information more quickly, as long as they pass through fewer intermediate nodes. In a co-authored network, institutions with a higher closeness centrality may be at the center of the network. This paper uses formula of closeness centrality to compare the closeness centrality of nodes in the network. The specific formula is as follows:

$$
C_{C}\left(n_{i}\right)=\sum_{i=1}^{n} \frac{1}{d\left(n_{i}, n_{j}\right)},
$$

where $d\left(n_{i}, n_{j}\right)$ is the shortest distance between node $n_{i}$ and node $n_{j}$ (that is, the number of lines included in the shortest path). The larger the value of $C_{C}\left(n_{i}\right)$, the closer the point is to the core of the network. In order to compare the closeness centrality of nodes in different networks, the relative closeness centrality is defined. The specific formula is as follows:

$$
C_{C}^{\prime}\left(n_{i}\right)=\frac{n-1}{C_{C}\left(n_{i}\right)}
$$

Although these three centrality indicators are relevant in the general network, they reflect the importance of nodes in the network from different perspectives. The degree centrality indicator characterizes the local center index, which measures the ability of nodes in the network to communicate with other nodes. Betweenness centrality considers the ability of one node to control other nodes. Closeness centrality considers the ability of the node to be uncontrolled.

We input the network models of the three stages 2000-2008, 2009-2013, and 2014-2018 into the software UCINET and calculate the degree centrality, the betweenness centrality after standardization, and the closeness centrality after standardization of nodes in network. The number of network nodes in the three phases is large, so the ten largest values of each indicator are selected as samples to analyze. The top 10 institutions with three highest centralities are listed separately, as shown in Tables 6-8. Table 9 shows the full names of all acronyms in Tables 6-8.

As can be seen from Tables 6-8, first of all, there is a similar commonality: that is, in this ranking, the number of Chinese universities based on the three centrality indicators in the evolution stage at the top ten is on the rise. This is especially evident in the data in Table 8 . Among the ten institutions with the highest closeness centrality, the number of institutions from China in the three stages is 5, 7, and 8, respectively, showing an increasing trend, indicating that in these three stages of the network, the overall status of Chinese Business School in the network is gradually rising. Their ability to contact other nodes, the ability to control nodes, and the ability to be controlled by other nodes have a relative improvement. Secondly, as shown in Table 6, the value of degree centrality generally rises in the three stages, indicating that in the stage of network evolution, the number of cooperation between institutions and other institutions and the number of cooperation objects are increasing. The scope of cooperation is also increasing. For the two indicators of betweenness centrality and closeness centrality after standardization, we can see that these two indicators have similar characteristics. In the three stages of network evolution, the values of these two indicators generally show an upward trend, indicating that each node's ability of controlling information and resources, ability of information transmission, and efficiency of information transmission are all improved. However, the values of some nodes with higher rankings are gradually decreasing in three stages, and the difference between the highest values and lowest values of each group is gradually decreasing. As shown in Table 7 during 2000-2008, the betweenness centrality of Hong Kong University of Science and Technology is 0.497 and that of Peking University is 0.023 . The difference between the two is 0.474. During 2009-2013, the betweenness centrality of Hong Kong University of Science 
TABLE 6: The top ten institutions' degree centrality in three stages.

\begin{tabular}{|c|c|c|c|c|c|c|}
\hline \multirow{2}{*}{ Rank } & \multicolumn{2}{|c|}{$2000-2008$} & \multicolumn{2}{|c|}{ 2009-2013 } & \multicolumn{2}{|c|}{$2014-2018$} \\
\hline & Institution name & $C_{D}\left(n_{i}\right)$ & Institution name & $C_{D}\left(n_{i}\right)$ & Institution name & $C_{D}\left(n_{i}\right)$ \\
\hline 1 & HKUST(C) & 126 & HKUST(C) & 122 & CityU(C) & 150 \\
\hline 2 & CUHK(C) & 76 & $\operatorname{CityU}(\mathrm{C})$ & 108 & HKUST(C) & 130 \\
\hline 3 & CityU(C) & 59 & CUHK(C) & 88 & PolyU(C) & 111 \\
\hline 4 & PolyU(C) & 41 & $\operatorname{HKU}(\mathrm{C})$ & 60 & Tsinghua Univ(C) & 90 \\
\hline 5 & $\mathrm{HKU}(\mathrm{C})$ & 39 & PolyU(C) & 59 & CUHK(C) & 90 \\
\hline 6 & Peking Univ(C) & 28 & Peking Univ(C) & 59 & SJTU(C) & 88 \\
\hline 7 & $\mathrm{UTA}(\mathrm{A})$ & 24 & SJTU(C) & 42 & $\mathrm{HKU}(\mathrm{C})$ & 86 \\
\hline 8 & NYU(A) & 22 & NUS(S) & 33 & Fudan $\operatorname{Univ}(\mathrm{C})$ & 79 \\
\hline 9 & NUS(S) & 21 & Fudan Univ(C) & 32 & Peking Univ(C) & 73 \\
\hline 10 & Cornell Univ(A) & 20 & $\mathrm{LU}(\mathrm{C})$ & 31 & NUS(S) & 72 \\
\hline
\end{tabular}

TABLE 7: The top ten institutions' betweenness centrality in three stages.

\begin{tabular}{|c|c|c|c|c|c|c|}
\hline \multirow{2}{*}{ Rank } & \multicolumn{2}{|c|}{$2000-2008$} & \multicolumn{2}{|c|}{ 2009-2013 } & \multicolumn{2}{|c|}{ 2014-2018 } \\
\hline & Institution name & $C_{B}^{\prime}\left(n_{i}\right)$ & Institution name & $C_{B}^{\prime}\left(n_{i}\right)$ & Institution name & $C_{B}^{\prime}\left(n_{i}\right)$ \\
\hline 1 & HKUST(C) & 0.497 & HKUST(C) & 0.274 & CityU(C) & 0.192 \\
\hline 2 & CUHK(C) & 0.254 & CityU(C) & 0.231 & HKUST(C) & 0.123 \\
\hline 3 & CityU(C) & 0.151 & CUHK(C) & 0.165 & PolyU(C) & 0.122 \\
\hline 4 & PolyU(C) & 0.13 & PolyU(C) & 0.105 & CUHK(C) & 0.066 \\
\hline 5 & $\mathrm{HKU}(\mathrm{C})$ & 0.066 & $\mathrm{HKU}(\mathrm{C})$ & 0.094 & Tsinghua Univ(C) & 0.071 \\
\hline 6 & UW(A) & 0.032 & Peking Univ(C) & 0.067 & SJTU(C) & 0.065 \\
\hline 7 & NUS(S) & 0.025 & $\mathrm{LU}(\mathrm{C})$ & 0.049 & Fudan Univ(C) & 0.06 \\
\hline 8 & NYU(A) & 0.024 & SJTU(C) & 0.032 & $\mathrm{HKU}(\mathrm{C})$ & 0.063 \\
\hline 9 & UoN(E) & 0.024 & NUS(S) & 0.031 & SHUFE(C) & 0.042 \\
\hline 10 & Peking Univ(C) & 0.023 & UW(A) & 0.031 & Peking Univ(C) & 0.042 \\
\hline
\end{tabular}

TABLE 8: The top ten institutions' closeness centrality in three stages.

\begin{tabular}{|c|c|c|c|c|c|c|}
\hline \multirow{2}{*}{ Rank } & \multicolumn{2}{|c|}{$2000-2008$} & \multicolumn{2}{|c|}{ 2009-2013 } & \multicolumn{2}{|c|}{$2014-2018$} \\
\hline & Institution name & $C_{C}^{\prime}\left(n_{i}\right)$ & Institution name & $C_{C}^{\prime}\left(n_{i}\right)$ & Institution name & $C_{C}^{\prime}\left(n_{i}\right)$ \\
\hline 1 & HKUST(C) & 0.638 & HKUST(C) & 0.582 & CityU(C) & 0.549 \\
\hline 2 & CUHK(C) & 0.565 & CityU(C) & 0.56 & HKUST(C) & 0.529 \\
\hline 3 & CityU(C) & 0.52 & CUHK(C) & 0.551 & PolyU(C) & 0.515 \\
\hline 4 & HKU(C) & 0.507 & $\mathrm{HKU}(\mathrm{C})$ & 0.51 & CUHK(C) & 0.508 \\
\hline 5 & PolyU(C) & 0.499 & PolyU(C) & 0.504 & SJTU(C) & 0.507 \\
\hline 6 & NYU(A) & 0.489 & NUS(S) & 0.485 & Peking Univ(C) & 0.5 \\
\hline 7 & UTA(A) & 0.489 & UW(A) & 0.48 & $\mathrm{HKU}(\mathrm{C})$ & 0.499 \\
\hline 8 & NUS(S) & 0.484 & $\mathrm{LU}(\mathrm{C})$ & 0.476 & NUS(S) & 0.497 \\
\hline 9 & Columbia Univ(A) & 0.477 & SJTU(C) & 0.473 & Fudan $\operatorname{Univ}(\mathrm{C})$ & 0.495 \\
\hline 10 & UPenn $(\mathrm{A})$ & 0.474 & $\mathrm{NU}(\mathrm{A})$ & 0.47 & $\mathrm{UW}(\mathrm{A})$ & 0.495 \\
\hline
\end{tabular}

Note. (C), Chinese university; (A), American university; (S), Singaporean university; (E), British university.

and Technology is 0.274 and that of the University of Washington is 0.031 . The difference between the two is 0.243. During 2014-2018, City University of Hong Kong has a betweenness centrality of 0.192 and Peking University has a betweenness centrality of 0.042 . The difference between the two is 0.15 . The same situation occurs in the near centrality. From 2000 to 2008, the Hong Kong University of Science and Technology's closeness centrality is 0.638 and that of the University of Pennsylvania is 0.474 . The difference between the two is 0.164 . During 2009-2013, the closeness centrality of the Hong Kong University of Science and Technology is 0.582 and that of Northwestern University is 0.47 . The difference between the two is 0.112. During 2014-2018, the closeness centrality of the City University of Hong Kong is 0.549 and that of the University of Washington is 0.495 , with a difference of 0.054 . Finally, we can see from the data that although the gap between the various data is decreasing, the top few in these tables are still fixed institutions: Hong Kong University of Science and Technology, City University of Hong Kong, Hong Kong Polytechnic University, Hong Kong University, etc. This shows that with the improvement of the overall level of the network, there are still some nodes located at the core of the network, controlling a large amount of information and resources in the network. In order to better present the changes in the number of different institutions at different stages, we have counted the number 
TABle 9: The full names of all acronyms in Tables 6-8.

Chinese university

HKUST: The Hong Kong University of Science and Technology

CityU: City University of Hong Kong

LU: Lingnan University

SJTU: Shanghai Jiao Tong University

Peking Univ: Peking University

SHUFE: Shanghai University of Finance and Economics

CUHK: The Chinese University of Hong Kong

HKU: The University of Hong Kong

PolyU: The Hong Kong Polytechnic University

Fudan Univ: Fudan University

Tsinghua Univ: Tsinghua University

American university

UTA: University of Texas at Austin

Cornell Univ: Cornell University

UPenn: University of Pennsylvania

Columbia Univ: Columbia University

Singaporean university

NUS: National University of Singapore

British university

UoN: University of Nottingham

NYU: New York University

UW: University of Washington

NU: Northwest University

and proportion of domestic universities, foreign universities, and other institutions in different stages. The results are shown in Table 10. From the results of Table 10, we can see that the three centrality analyses show similar results. First of all, in horizontal comparison, the number of institutions in the same ranking position, the number and proportion of domestic universities in different stages are on the rise, the number and proportion of foreign universities are declining. Secondly, in the vertical view, although the top ten domestic universities have always had a quantitative advantage, in terms of proportion, the number of domestic universities in the top 30 and the top 50 is gradually decreasing. On the contrary, the proportion of foreign universities has been on the rise; it shows that the overall status of domestic universities in the network has improved, but it is still relatively low compared with foreign universities. Other institutions include enterprises and research institutions. From the data changes in the number and proportion of other institutions, it can be seen that their numbers and proportions are on the rise. It shows that many universities have begun to cooperate with heterogeneous institutions such as enterprises and research institutions.

In general, the changes of all data in the four tables indicate that as the network continues to evolve, the number of nodes in the network and the size of the network are increasing, and the nodes' ability to control information and transfer capabilities and information transfer efficiency are improved. The gap between nodes in these capabilities is gradually narrowing. The phenomenon that a few nodes control the entire network still exists, but the influence of these nodes is gradually decreasing. In the process of network evolution in different stages, the number and proportion of domestic universities in the network are relatively low compared with foreign universities, but overall, it has been greatly improved. The situation reflected in the coauthored papers is that more and more institutions are trying to cooperate with other nonnetwork core institutions to produce results. The scope of cooperation is gradually expanding, and the outputs of cooperation are gradually increasing. More institutions are starting to work with heterogeneous institutions such as enterprises and research institutions to find new ways of cooperation $[47,48]$. At the same time, in the three stages of IRC network, the node capacity of Chinese Business School has gradually increased. According to Figure 1, the number of papers published by Chinese Business School is also on the rise. Then, these three indicators that judge the node's capacity of institution may affect the paper quality of an institution published on UTD24 to a certain extent. Therefore, these three indicators are listed as the influencing factors as described in Section 7.

\section{Hotspot Analysis of International Cooperation Network of Chinese Business School}

After analyzing the evolution of the international cooperation network at the institutional level, we will focus on the research hotspots of the joint network. Research hotspots will have a certain impact on the evolution of the research institution's network, and it will drive different institutions to cooperate with each other. At the same time, it lays a foundation for the study of the last part of the influencing factors in this paper, so in this part, we analyze the research hotspots of various institutions within the network.

6.1. Analysis Method. In this part, we mainly use three research methods. The co-word analysis method belongs to the content analysis method, which is used to analyze the cooccurrence relationship and co-occurrence intensity of a group of word pairs in the same document, reflecting the relationship between keywords and keywords, revealing the internal structure and trends of a research field.

Cluster analysis: this is a very active method of bibliometrics and visualization. According to the strength between keywords and keywords, some keywords with strong cooccurrence intensity are grouped together to form clusters. In this paper, we use the clustering method in CiteSpace to classify the categories of keywords, comprehensively compare the rankings of different kinds of clustering methods, and use the keywords with higher ranking according to different clustering methods as the subject of the cluster in order to reflect the research content and research direction of clustering. Specifically, we extract the keywords of 1953 papers published by the Chinese University Business School in the UTD24 journal, input these keywords into the software CiteSpace, and remove the keywords with a frequency of one. The remaining keywords are 656 . However, there is no way for individuals to identify research content and research direction based on high-frequency keywords. Therefore, this study used CiteSpace to cluster these 
TABle 10: Number and proportion of different type of institutions in top 10, 30, and 50 based on centrality analysis.

\begin{tabular}{|c|c|c|c|c|c|c|c|c|c|}
\hline \multirow{2}{*}{$\begin{array}{l}\text { Stages } \\
\text { Indicator }\end{array}$} & \multicolumn{3}{|c|}{$2000-2008$} & \multicolumn{3}{|c|}{$2009-2013$} & \multicolumn{3}{|c|}{$2014-2018$} \\
\hline & \multicolumn{9}{|c|}{ Degree centrality } \\
\hline Rank & (1) & (2) & (3) & (1) & (2) & (3) & (1) & (2) & (3) \\
\hline Top10 & $6(60 \%)$ & $4(40 \%)$ & 0 & $9(90 \%)$ & $1(10 \%)$ & 0 & $9(90 \%)$ & $1(10 \%)$ & 0 \\
\hline Top30 & $11(37 \%)$ & $18(60 \%)$ & $1(3 \%)$ & $14(47 \%)$ & $14(47 \%)$ & $2(6 \%)$ & $13(43 \%)$ & $15(50 \%)$ & $2(7 \%)$ \\
\hline Top50 & $11(22 \%)$ & $37(74 \%)$ & $2(4 \%)$ & $16(32 \%)$ & $30(62 \%)$ & $4(8 \%)$ & $19(38 \%)$ & $27(54 \%)$ & $4(8 \%)$ \\
\hline Indicator & \multicolumn{9}{|c|}{ Betweenness centrality } \\
\hline Rank & (1) & (2) & (3) & (1) & (2) & (3) & $(1)$ & (2) & (3) \\
\hline Top10 & $6(60 \%)$ & $4(40 \%)$ & 0 & $8(80 \%)$ & $2(20 \%)$ & 0 & 10 & 0 & 0 \\
\hline Top30 & $10(33 \%)$ & $19(63 \%)$ & $1(3 \%)$ & $18(60 \%)$ & $11(37 \%)$ & $1(3 \%)$ & $18(60 \%)$ & $10(33 \%)$ & $2(7 \%)$ \\
\hline Top50 & $13(26 \%)$ & $35(70 \%)$ & $2(4 \%)$ & $20(40 \%)$ & $26(52 \%)$ & $4(8 \%)$ & $23(46 \%)$ & $23(46 \%)$ & $4(8 \%)$ \\
\hline Indicator & \multicolumn{9}{|c|}{ Closeness centrality } \\
\hline Rank & (1) & (2) & (3) & (1) & $(2)$ & (3) & (1) & (2) & (3) \\
\hline Top10 & $5(50 \%)$ & $5(50 \%)$ & 0 & $7(70 \%)$ & $3(30 \%)$ & 0 & $8(80 \%)$ & $2(20 \%)$ & 0 \\
\hline Top30 & $8(27 \%)$ & $21(70 \%)$ & $1(3 \%)$ & $14(47 \%)$ & $15(50 \%)$ & $1(3 \%)$ & $14(47 \%)$ & $14(47 \%)$ & $2(6 \%)$ \\
\hline Top50 & $11(22 \%)$ & $37(74 \%)$ & $2(4 \%)$ & $16(32 \%)$ & $31(62 \%)$ & $3(6 \%)$ & $18(36 \%)$ & $28(56 \%)$ & $4(8 \%)$ \\
\hline
\end{tabular}

Note. (1), the number and proportion of domestic universities; (2), the number and proportion of foreign universities; (3), the number and proportion of other institutions (enterprise or research institute).

keywords and obtained 32 clusters. The number and name of the cluster are shown in Table 11.

Strategic diagram analysis is mainly used to analyze the structure of research hotspots in a certain field and its changing trends. The strategic diagram is two-dimensional coordinate graph. On the basis of the previous cluster analysis, the clustering attention index is the abscissa, and the novelty of the cluster is the ordinate, and the strategic diagram is established. From the established strategic diagram, we can see the location of each cluster in the entire research area. According to the distribution of clusters in the four quadrants, the research status of the research field and the future development trends and changes can be described as shown in Figure 3.

The novelty and attention degree of clusters located in the first quadrant are greater than 0 , indicating that the research content represented by these clusters is highly concerned and belongs to the research and development hotspots in recent years. Clusters in the first quadrant are the core content of the whole research field. We call the research area in the first quadrant "core field." The novelty in the second quadrant is greater than 0 , and the attention degree is less than 0 , indicating that the research content represented by these clusters belongs to new hotspots in recent years, but these clusters are less concerned. As soon as the attention degree increases, the clusters in the second quadrant will move to the first quadrant, becoming a more mature research hotspot. Therefore, the research field in the second quadrant is called "potential field." The novelty and attention degree of clusters located in the third quadrant called "marginal field" are less than 0, indicating that the research content represented by these clusters is not highly concerned and there are few studies in recent years, which belong to the marginalized research content. The clusters in the fourth quadrant called basic field have a degree of attention greater than 0 , and the novelty is less than 0 , indicating that the research content represented by these clusters has attracted much attention, but it is not a research hotspot in recent years and belongs to the basic research content. Although there have been few studies in recent years, research in this
TABLE 11: The number and name of the cluster.

\begin{tabular}{lc}
\hline & The name of cluster \\
\hline 1 & External validity \\
2 & Consumer behavior \\
3 & Underinvestment \\
4 & Discrete choice \\
5 & Socioeconomic inequality \\
6 & Corporate governance \\
7 & Social preference \\
8 & Coordination \\
9 & Decision support \\
10 & Demand uncertainty \\
11 & Asset pricing \\
12 & Financial network \\
13 & Social media \\
14 & Stock return \\
15 & Mobile analytics \\
16 & Merger and acquisition \\
17 & Valuation uncertainty \\
18 & Risk management \\
19 & Fairness \\
20 & Robust optimization \\
21 & Information systems \\
22 & Conflict \\
23 & Priority scheduling \\
24 & Information goods \\
25 & Social ties \\
26 & Customer lifetime value \\
27 & Tax collection \\
28 & Managerial ownership \\
29 & Approximation algorithm \\
30 & Competing risks model \\
31 &
\end{tabular}

field must be based on these clusters, especially some clusters with high attention.

6.2. Analysis Results. We calculate the average collinear time of each cluster according to the time when the keyword 


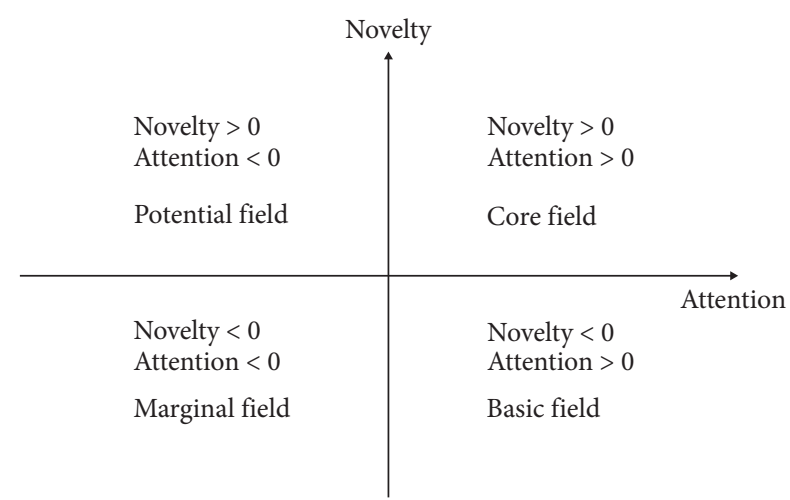

FIGURE 3: Strategic diagram.

reaches the threshold to reflect the average duration of the cluster and then calculate the average duration of each cluster and the average duration of all the co-occurring keywords. The average difference is called "novelty." The value has positive and negative points. If the value is positive, it indicates that the study time is relatively late. If the value is negative, it indicates that the research time is earlier. If there are $N$ co-occurring keywords, $K$ clusters are formed, and there are $M$ keywords in each cluster. $Y$ is used to represent the year in which the novelty is calculated as follows:

$$
N D_{i}=\frac{1}{M} \sum_{j=1}^{m} Y_{i j}-\frac{1}{N} \sum_{g=1}^{n} Y_{g}, \quad i=1,2,3, \ldots, k
$$

where $N D_{i}$ is the novelty of the $i$ th cluster, $(1 / M) \sum_{j=1}^{m} Y_{i j}$ is the co-occurrence annual average of the $M$ keywords of the $i$ th cluster, and $(1 / N) \sum_{g=1}^{n} Y_{g}$ is the co-occurrence annual average of the $N$ keywords that are co-occurring.

We calculate the average co-occurrence frequency of each cluster according to the co-occurrence frequency of each keyword and then calculate the average co-occurrence frequency of each cluster and the average co-occurrence frequency of all co-occurring keywords, thereby obtaining the degree of attention of a certain cluster. The value also has positive and negative points. If the value is positive, it indicates that the research of the content represented by the cluster is highly concerned; if the value is negative, it indicates that the research of the content represented by the cluster is lower concerned. If there are $N$ co-occurring keywords, $K$ clusters are formed, and there are $M$ keywords in each cluster. When $F$ is used to represent the co-occurrence frequency, the formula of attention degree is

$$
C_{i}=\frac{1}{M} \sum_{j=1}^{m} F_{i j}-\frac{1}{N} \sum_{g=1}^{n} F_{g}, \quad i=1,2,3, \ldots, k,
$$

where $C_{i}$ is the attention degree of the $i$ th cluster, $(1 / M) \sum_{j=1}^{m} F_{i j}$ is the average value of the co-occurrence frequency of the $M$ keywords of the $i$ th cluster, and $(1 / N) \sum_{g=1}^{n} F_{g}$ is the co-occurrence frequency average of the $\mathrm{N}$ keywords co-occurring.

This part extracts the keywords of 1953 papers published by China Business School in UTD24 journals from 20002018 (Figure 4), imports these keywords into the software
CiteSpace, and removes the keywords whose frequency is one. The remaining keywords are 656. Among the 656 keywords, "Model" has the highest frequency of words $($ Freq $=83$ ), but there is no way for individuals to identify research content and research direction based on highfrequency keywords. Therefore, this study used CiteSpace to cluster these keywords and obtained 32 clusters.

The strategic diagram of keyword clustering on UTD24 journals published by Chinese Business School from 2000-2018 is shown in Figure 4. In strategic diagram, Points represent the locations of the different clusters in the quadrant. The number in the Figure 4 is the number of cluster in Table 11, cluster 19 is the cluster with the highest degree of attention, and cluster 27 and cluster 32 are the clusters with the highest degree of novelty. According to the meaning of each quadrant of the strategic diagram, the clusters in the first quadrant are $9,10,12,16,17,18,21,22$, $25,27,28,29$, and 30 , and these Clusters belong to the "core field," and this kind of cluster is not only highly concerned but also belongs to research hotspots in recent years. Cluster 29 has the highest degree of attention and mainly includes keywords such as "correlated demand," "approximation algorithm," and "perishable inventory." The highest degree of novelty is cluster 27 , which mainly includes "tax collection," "tax policy enforcement," and other keywords. Clusters 4, 5, 6, 11, 24, 26, and 32 are located in the second quadrant, indicating that the research content represented by these clusters belongs to the research hotspots in the research of Chinese Business School in the UTD24 journals published from 2000 to 2018. Although the keywords represented by these clusters are not well received, they may become the core content of management research in the future. In the second quadrant, the highest degree of novelty is cluster 32, which mainly includes keywords such as "value premium" and "competing risks model." The clusters in the third quadrant are $1,2,3,7,8,14$, and 31 , mainly related to "patent citation," "social cognitive theory," "systematic quality feedback system," and "socially endorsed people." These topics have less attention and novelty than zero, which is a marginalized research content that has received little attention in the past and present. The clusters located in the fourth quadrant have $13,15,19,20$, and 23 , indicating that the topics represented by these clusters belong to the basic research content, which is not a new hotspot of current research from the novelty, but there are many papers on the topic of these topics.

After dividing 32 clusters into four quadrants, we can see that there are 20 clusters with a novelty greater than zero, and 18 clusters with attention greater than zero, which are the clusters in the first, second, and fourth quadrants of the strategic graph. We regard the keywords contained in the 20 clusters with novelty greater than zero as the new research hotspots in the relevant research field and regard the keywords contained in the 18 clusters with attention greater than zero as the research hotspots widely concerned by recent scholars. Next, we begin to examine the number of clusters in the keywords published in the UTD24 journals by various Chinese Business School, which meet the above condition of clusters. It is counted whether the novelty of the 


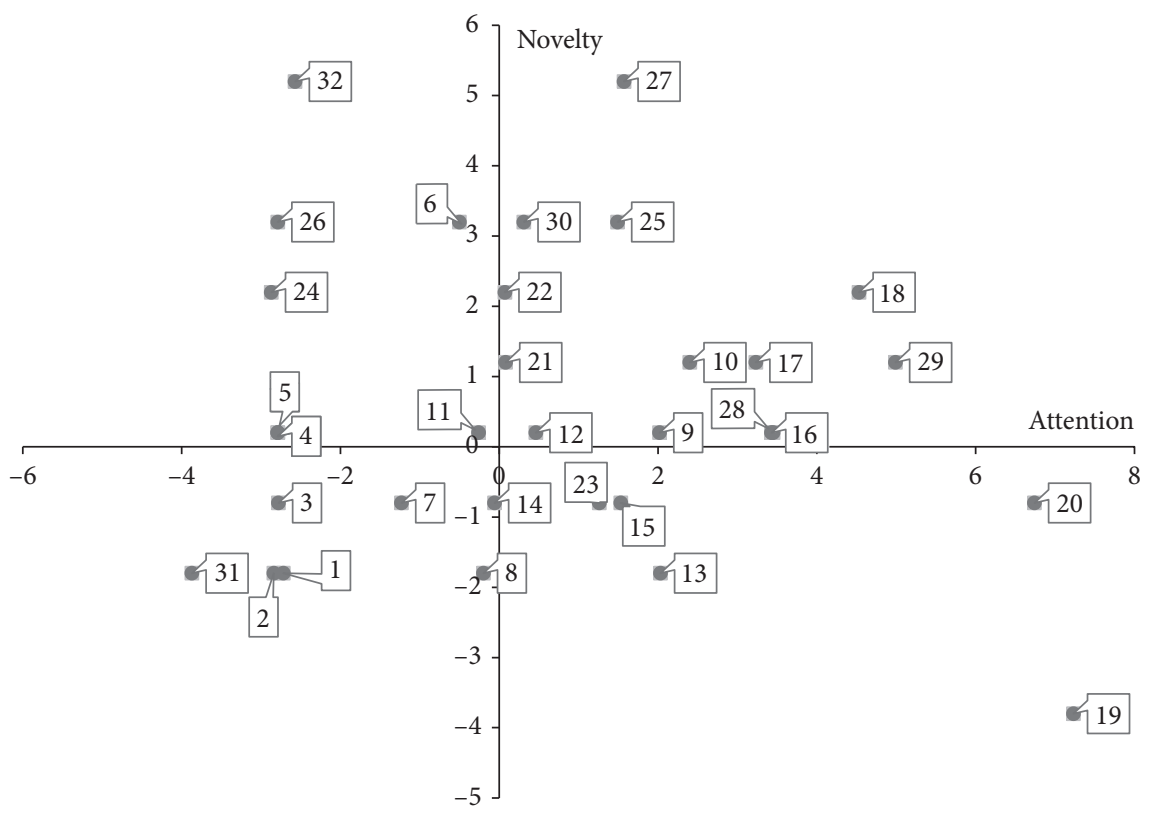

Figure 4: The strategic diagram of keyword clustering on UTD journals published by Chinese business school from 2000-2018.

cluster of the various keywords published by the Chinese Business School in the UTD24 journals is greater than zero or whether the attention of cluster of each keyword in the paper is greater than zero. That is, this paper has analyzed whether these papers' keywords belong to the 20 clusters whose novelty is greater than zero, or whether keywords belong to the 18 clusters whose attention is greater than zero. At the same time, we record the number of clusters that meet two conditions above, respectively. We refer to the number of clusters whose keywords belong to novelty greater than zero in a paper published by an institution as the degree of novelty, denoted as $D(n)$, where $D(n)$ is greater than or equal to zero and less than or equal to 20 . We refer to the number of clusters whose keywords belong to attention greater than zero in a paper published by an institution as the degree of attention, denoted as $D(a)$, where $D(a)$ is greater than or equal to zero and less than or equal to 18. If a keyword in a paper published by an institution belongs to a cluster with novelty greater than zero and attention greater than zero, then $D(n)$ of the institution is recorded as 1 and $D(a)$ of the institution is recorded as 1 . If a paper published by an institution contains multiple keywords and the novelty and attention of multiple clusters to which these keywords belong are both greater than zero, then $D(n)$ and $D(a)$ of the institution are both recorded as the number of clusters that meet the novelty and attention greater than zero. If multiple papers published by an institution involve the same field of cluster, the number of clusters is not counted repeatedly, which means the value of $D(n)$ and $D(a)$ remain unchanged. In other words, the greater the number of clusters whose novelty or attention is greater than zero in papers published by an institution, the bigger the corresponding $D(n)$ and $D(a)$ are. The corresponding $D(n)$ and $D(a)$ of this institution are bigger. We use $D(n)$ and $D(a)$ to examine whether the research content of an institution's published papers is at the forefront of research and whether these research contents have been the focus of research in the academia in recent years.

There are 143 Chinese institutions, including business schools and enterprises, which have published papers in UTD24 journals. There are 63 institutions that have published one paper. The institutions that have published only one paper have lower reference values for the corresponding indicators, so we have removed these institutions from the sample. Only those institutions that have published more than one paper are retained. We counted $D(n)$ and $D(a)$ of these 80 institutions to pave the way for the correlation analysis of the influencing factors in the next section.

\section{Analysis on the Influence Factors of Paper Quality}

In order to better study the academic research level of Chinese Business School and propose some specific management inspirations for colleges with different academic levels, this paper will explore the influencing factors of paper quality published by Chinese Business School in UTD24 journals. The sample of empirical analysis was selected as a Chinese institution with two or more papers published. First of all, the academic level of an institution is measured by paper quality published by the institution. In this part, paper quality is defined in two aspects. The first aspect is the quantitative level indicator: the total number of papers published by the institution refers to the total number of papers published by an institution in the UTD24 journals from 2000 to 2018. The second indicator is citations per paper which refers to the number of times each paper published by an organization has been cited. These indicators are obtained from the Web of Science database.

Secondly, this paper explores the factors that may affect paper quality. The third part of this paper analyzes the 
TABLe 12: Descriptive statistics between variables.

\begin{tabular}{|c|c|c|c|c|}
\hline Variables & Min & Max & Mean & STDEV \\
\hline Total number of published papers & 2 & 553 & 35 & 81.386 \\
\hline Citations per paper & 0 & 146.13 & 34.902 & 32.798 \\
\hline Degree & 1 & 232 & 32.55 & 47.28 \\
\hline$(N)$ closeness & 0.307 & 0.593 & 0.419 & 0.062 \\
\hline$(N)$ betweenness & 0 & 0.200 & 0.013 & 0.036 \\
\hline$D(n)$ & 0 & 17 & 5.613 & 5.164 \\
\hline$D(a)$ & 0 & 17 & 5.450 & 5.031 \\
\hline $\begin{array}{l}\text { The sum of the years in which the paper was } \\
\text { published }\end{array}$ & 1 & 19 & 6.725 & 5.104 \\
\hline Number of journals published & 1 & 24 & 7.338 & 6.457 \\
\hline Number of countries cooperating & 0 & 14 & 4.400 & 3.634 \\
\hline
\end{tabular}

centrality of the network evolution process. The three indicators used in the analysis, such as the degree centrality, closeness centrality after standardization, and betweenness centrality, may have a certain degree of influence on paper quality because the location of an academic institution in the network can have a large impact on the academic outcomes of its output. Therefore, this paper uses UCINET software to analyze the co-occurrence matrix of Chinese institutions. The degree centrality, the closeness centrality, and the betweenness centrality after standardization of the Chinese institutions in the network from 2000 to 2018 are calculated and taken as part of the influencing factors. $D(n)$ and $D(a)$ studied in the fourth part of this paper may also have an impact on the quality of academic papers because the research content and the degree of novelty and attention on the topic will also have a certain influence on the paper quality. Research quality is not affected, regardless of whether a scholar collaborates with different or the same coauthors [49]. Therefore, we also include the Chinese institution's $D(n)$ and $D(a)$ into the scope of consideration. In addition to the indicators used to measure the influencing factors mentioned in this paper, this paper also considers that some other factors may affect the paper quality: for example, the number of countries that cooperate with the institution, the number of journals that publish the institution's papers (only in the UTD24 journals), and the sum of the years in which the paper was published papers from 2000 to 2018. These three indicators may have a certain degree of influence on the quality of academic papers from the aspects of academic transnational cooperation, the coverage of academic research, and the time dimension of academic publications.

Combining the above influencing factors, we constructed two multiple linear regression models. The dependent variables of the two models are the total number of published papers and citations per paper representing the quality of academic papers. The independent variables are the degree centrality, the closeness centrality after standardization, the betweenness centrality after standardization, $D(n), D(a)$, the number of countries cooperating with the institution, the number of journals that published the paper of the institution, and the sum of the years in which the paper was published from 2000 to 2018. The statistical method was to use the software SPSS to perform stepwise regression between samples. Before conducting an empirical analysis, we first performed descriptive statistical analysis of independent and dependent variables, as shown in Table 12.

As can be seen from Table 12, each Chinese institution can publish 35 papers in UTD24 journals from 2000 to 2018, and each paper can be cited nearly 35 times. On average, each Chinese institution can have a partnership with 32 institutions. However, when returning to the maximum and minimum values, we found the same feature that the difference between the minimum and maximum values of most variables is large, especially in the total number of published papers, citation per paper, and the degree centrality although the mean values of these variables are small, indicating that the academic level between individuals is still very different. The gap between the closeness centrality and the betweenness centrality is small. It is indicated that due to the size of the network, the gap between the control of the internal information of the network and the difficulty of reaching other nodes is not large.

The model constructed in this paper and the results of the regression analysis are shown in Table 13. The independent variables that do not appear in the table indicate that they do not have a significant influence on the dependent variables. Through stepwise regression analysis, we can see that the degree centrality of the institution has a significant positive impact on the total number of published papers of an institution in model one, which means the more cooperation an institution has, the more papers it publishes. Similarly, the higher the betweenness centrality of an institution, the stronger its ability to control information and resources and the more likely the node is at the core of the network. Such nodes control the communication between other nodes because institutions with high betweenness centrality can control the flow of information and resources, so the institution may assume the role of a knowledge intermediary and the number of published papers by an institution will be higher.

It can be seen from model 2 that there is a significant negative influence on the degree of novelty and the citations per paper, indicating that the higher the novelty of a paper published by an institution, the lower the citation frequency of papers published by this institution. In the academic field, although the topic of an institution's paper is novel enough, 
TABLE 13: Results of regression analysis.

\begin{tabular}{|c|c|c|c|}
\hline & Standardization coefficient & $T$ & Sig. \\
\hline \multicolumn{4}{|l|}{ Model 1} \\
\hline$(N)$ betweenness & 0.692 & 7.754 & 0.000 \\
\hline Degree & 0.285 & 3.189 & 0.002 \\
\hline \multicolumn{4}{|l|}{ Model 2} \\
\hline$D(n)$ & -1.385 & -3.232 & 0.002 \\
\hline$D(a)$ & 1.104 & 2.317 & 0.023 \\
\hline Number of countries cooperating & 0.550 & 2.139 & 0.036 \\
\hline
\end{tabular}

it is likely to be rejected by other scholars in the academia, or the topic has not been accepted by academics, so the probability of such papers being cited is relatively low. The degree of attention has a significant positive impact on the citations per paper. If the topic or research direction of a paper is widely concerned by the academic community, then naturally this paper will bring some help to the scholars' research afterwards, and then the papers published by the institution will be cited frequently. The number of countries that cooperate with the institution has a significant positive impact on the citations per paper of an institution. The more the number of cooperating countries in an institution, the higher the citation frequency per published paper and the more likely they are to reach out to academics from different countries and academia, thus increasing their influence in the international academic community, so that their academic achievements will be more concerned and cited by more people.

\section{Conclusions}

This paper first counts the number of papers published by Chinese Business School in the UTD24 journals from 2000 to 2018 and finds that there is a certain degree of phased characteristics in the number of papers in these 19 years. According to this staged feature, combining the effective size, betweenness centralization, and average distance in social network analysis indicators, this paper uses the formula of entropy in information theory and the optimal segmentation theory of network time evolution to divide the international research collaboration network of Chinese Business School into three phases from the time perspective: 2000 to 2008,2009 to 2013, and 2014 to 2018, in order to analyze the IRC network of Chinese Business School.

After dividing the network evolution stage, this paper uses the social network analysis method to analyze the evolution of IRC network of the Chinese Business School in these three stages from the overall indicators and the individual indicators of the network. From the perspective of the overall network indicators, the network scale and the number of edges of the IRC network of the three phases are gradually increasing, which proves that more and more institutions such as business schools, research institutions, and enterprises have joined the IRC network and the number of cooperation between them is also increasing. But, the information transmission efficiency inside the network is still at a low level, and the degree of aggregation in network is still weak. From the perspective of individual indicators, with the continuous development of the network, the ability of node control information and information transmission and information transmission efficiency have been significantly improved. The gap between nodes in these capabilities is gradually narrowing. Although the phenomenon that a few nodes control the entire network still exists, the impact of these nodes is gradually decreasing. In the process of network evolution in different stages, the number and proportion of Chinese Business School are relatively low compared with foreign universities, but overall, there has been a big improvement. The international co-authored paper reflects the fact that more and more institutions are trying to collaborate with other nonnetwork core institutions and produce academic results. The scope of their cooperation has gradually expanded, and the results of cooperation have gradually increased. There are also more and more institutions that are starting to work with heterogeneous institutions such as companies and research institutions to find new ways of cooperation. Through the research on the institutions represented by the nodes in this section of the three-staged IRC network, it is concluded that the three centrality indicators of the institution in the network are the influencing factors that may affect the paper quality of an institution.

Subsequently, this paper studied the research hotspots of papers published by Chinese Business School in UTD24 journals. The keywords in the paper were divided into 32 categories by the clustering method. The paper has studied whether research contents of these clusters are the core area of the research. At the same time, this paper introduces the two indicators: $D(n)$ and $D(a)$, which can reflect the degree of novelty and attention of an institution's research direction or research content. These two indicators are regarded as the influencing factors affecting the paper quality as described in Section 7.

The last part of the paper studies the influencing factors of paper quality which includes the total number of papers and citations per paper published by an institution. The study found that the degree centrality and betweenness centrality of an institution have a significant positive impact on the total number of papers. The degree of attention of an institution's thesis topic and the number of countries cooperating with the institution have a significant positive impact on the citations per paper. The degree of novelty of the institution's topic selection has a significant negative impact on the citations per paper. In general, the Chinese institutions that publish papers can be roughly divided into three types. The number of publications of high-level papers 
and the citations per paper are both large in the first institution, and paper quality is at a high level. The number of published papers in the second institution is itself small, and the citations per paper are small. For this type of Chinese institution, you can first improve the number of publications of high-level papers, trying to engage in academic exchanges and cooperation with more institutions, which is conducive to the emergence of new research sites and the birth of academic achievements. The number of papers in the third institution is itself large, but the citation per papers is less. This type of Chinese institution can choose some relatively more focused topics or research content for in-depth research or cooperate with institutions in many countries, which will help to improve the frequency of citations and the degree of attention, thus enhancing paper quality.

At the same time, this paper has certain limitations, mainly the following two points. Firstly, the research sample of this paper is from the paper published by Chinese Business School in UTD24 from 2000 to 2018. The conclusion will be time-sensitive. The study results are only obtained from the data of 19 years from 2000 to 2018 . Subsequent evolution and the influencing factors of the paper quality require further research. Secondly, the scope of the study is Chinese Business School. Based on China's current national conditions and academic research, the conclusions and opinions given may be more applicable to business schools in China. Other countries may have certain similarities but further research is needed.

\section{Data Availability}

The data used to support the findings of this study are available from the corresponding author upon request.

\section{Conflicts of Interest}

The authors declare that there are no conflicts of interest regarding the publication of this paper.

\section{Acknowledgments}

This research was sponsored by the Seed Foundation of Innovation and Creation for Graduate Students in Northwestern Polytechnical University (grant no. ZZ2019238) and the Fundamental Research Funds for the Central Universities (grant no. 3102019JC06).

\section{References}

[1] X. Liu, J. Bollen, M. L. Nelson, and H. Van de Sompel, "Coauthorship networks in the digital library research community," Information Processing \& Management, vol. 41, no. 6, pp. 1462-1480, 2005.

[2] T. He, "International scientific collaboration of China with the G7 countries," Scientometrics, vol. 80, no. 3, pp. 571-582, 2009.

[3] M. Coccia and L. Wang, "Evolution and convergence of the patterns of international scientific collaboration," Proceedings of the National Academy of Sciences of the United States of America, vol. 113, no. 8, pp. 2057-2061, 2016.

[4] B. Bozeman, D. Fay, and C. P. Slade, "Research collaboration in universities and academic entrepreneurship: the-state-of- the-art," The Journal of Technology Transfer, vol. 38, no. 1, pp. 1-67, 2013.

[5] J. N. Cummings and S. Kiesler, "Coordination costs and project outcomes in multi-university collaborations," Research Policy, vol. 36, no. 10, pp. 1620-1634, 2007.

[6] S. Kumar, V. A. Rohani, and K. Ratnavelu, "International research collaborations of ASEAN Nations in economics, 1979-2010," Scientometrics, vol. 101, no. 1, pp. 847-867, 2014.

[7] M. Coccia and B. Bozeman, "Allometric models to measure and analyze the evolution of international research collaboration," Scientometrics, vol. 108, no. 3, pp. 1065-1084, 2016.

[8] B. Bozeman, M. Gaughan, J. Youtie, C. P. Slade, and H. Rimes, "Research collaboration experiences, good and bad: dispatches from the front lines," Science and Public Policy, vol. 43, no. 2, pp. 226-244, 2015.

[9] S. Lee and B. Bozeman, "The impact of research collaboration on scientific productivity," Social Studies of Science, vol. 35, no. 5, pp. 673-702, 2005.

[10] A. F. J. van Raan, "The influence of international collaboration on the impact of research results," Scientometrics, vol. 42, no. 3, pp. 423-428, 1998.

[11] Z. L. He, X. S. Geng, and C. Campbell-Hunt, "Research collaboration and research output: a longitudinal study of 65 biomedical scientists in a New Zealand university," Research Policy, vol. 38, no. 2, pp. 306-317, 2009.

[12] E. Y. Li, C. H. Liao, and H. R. Yen, "Co-authorship networks and research impact: a social capital perspective," Research Policy, vol. 42, no. 9, pp. 1515-1530, 2013.

[13] J. Hahn, J. Y. Moon, and C. Zhang, "Emergence of new project teams from open source software developer networks: impact of prior collaboration ties," Information Systems Research, vol. 19, no. 3, pp. 369-391, 2008.

[14] M. E. J. Newman, "The structure of scientific collaboration networks," Proceedings of the National Academy of Sciences of the United States of America (PNAS), vol. 98, no. 2, pp. 404-409, 2001.

[15] M. E. J. Newman, "Co-authorship networks and patterns of scientific collaboration," Proceedings of the National Academy of Sciences, vol. 101, no. Supplement 1, pp. 5200-5205, 2004.

[16] J. Li and Y. Li, "Patterns and evolution of co-authorship in China's humanities and social sciences," Scientometrics, vol. 102, no. 3, pp. 1997-2010, 2015.

[17] M. Callon, J. P. Courtial, and F. Laville, "Co-word analysis as a tool for describing the network of interactions between basic and technological research: the case of polymer chemistry," Scientometrics, vol. 22, no. 1, pp. 155-205, 1991.

[18] D. J. Brass, J. Galaskiewicz, H. R. Greve, and W. Tsai, "Taking stock of networks and organizations: a multilevel perspective," Academy of Management Journal, vol. 47, no. 6, pp. 795-817, 2004.

[19] C. S. Wagner and L. Leydesdorff, "Network structure, selforganization, and the growth of international collaboration in science," Research Policy, vol. 34, no. 10, pp. 1608-1618, 2005.

[20] T. W. Valente, "Social network thresholds in the diffusion of innovations," Social Networks, vol. 18, no. 1, pp. 69-89, 1996.

[21] E. Abrahamson and L. Rosenkopf, "Social network effects on the extent of innovation diffusion: a computer simulation," Organization Science, vol. 8, no. 3, pp. 289-309, 1997.

[22] F. X. Molina-Morales and M. T. Martínez-Fernández, "Social networks: effects of social capital on firm innovation," Journal of Small Business Management, vol. 48, no. 2, pp. 258-279, 2010.

[23] R. Aalbers, W. Dolfsma, and O. Koppius, "Rich ties and innovative knowledge transfer within a firm," British Journal of Management, vol. 25, no. 4, pp. 833-848, 2014. 
[24] E. Bakshy, I. Rosenn, C. Marlow et al., "The role of social networks in information diffusion," in Proceedings of the 21st International Conference on World Wide Web, Lyon, France, April 2012.

[25] N. Liu and J. Guan, "Dynamic evolution of collaborative networks: evidence from nano-energy research in China," Scientometrics, vol. 102, no. 3, pp. 1895-1919, 2015.

[26] S. Kumar and J. M. Jan, "Mapping research collaborations in the business and management field in Malaysia, 1980-2010," Scientometrics, vol. 97, no. 3, pp. 491-517, 2013.

[27] T. D. Fry, J. M. Donohue, B. A. Saladin, and G. Shang, "The internationalisation of operations management research," International Journal of Production Research, vol. 53, no. 16, pp. 4857-4887, 2015.

[28] M. A. Koseoglu, "Mapping the institutional collaboration network of strategic management research: 1980-2014," Scientometrics, vol. 109, no. 1, pp. 203-226, 2016.

[29] F. Niu and J. Qiu, "Network structure, distribution and the growth of Chinese international research collaboration," Scientometrics, vol. 98, no. 2, pp. 1221-1233, 2014.

[30] A. J. Nederhof, "Bibliometric monitoring of research performance in the social sciences and the humanities: a review," Scientometrics, vol. 66, no. 1, pp. 81-100, 2006.

[31] P. Zhou and L. Bornmann, "An overview of academic publishing and collaboration between China and Germany," Scientometrics, vol. 102, no. 2, pp. 1781-1793, 2015.

[32] Z. Wang, H. Zhao, and Y. Wang, "Social networks in marketing research 2001-2014: a co-word analysis," Scientometrics, vol. 105, no. 1, pp. 65-82, 2015.

[33] M. Coccia, "General properties of the evolution of research fields: a scientometric study of human microbiome, evolutionary robotics and astrobiology," Scientometrics, vol. 117, no. 2, pp. 1265-1283, 2018.

[34] K. A. Heischmidt and P. Gordon, "Rating of marketing publications: impact of accreditation and publication history," Journal of Education for Business, vol. 68, no. 3, pp. 152-158, 1993.

[35] F. J. González, C. B. Castro, J. C. C. Bueno et al., "Dominant approach in the field of management," International Journal of Organizational Analysis, vol. 9, no. 9, pp. 327-353, 2013.

[36] S. T. Silva and A. A. C. Teixeira, "On the divergence of evolutionary research paths in the past 50 years: a comprehensive bibliometric account," Journal of Evolutionary Economics, vol. 19, no. 5, pp. 605-642, 2009.

[37] R. Coe and I. Weinstock, "Evaluating the management journals: a second look," Academy of Management Journal, vol. 27, no. 3, pp. 660-666, 1984.

[38] J. L. Johnson and P. M. Podsakoff, "Journal influence in the field of management: an analysis using Salancik's index in a dependency network," Academy of Management Journal, vol. 37, no. 5, pp. 1392-1407, 1994.

[39] T. Dehdarirad, A. Villarroya, and M. Barrios, "Research trends in gender differences in higher education and science: a co-word analysis," Scientometrics, vol. 101, no. 1, pp. 273-290, 2014.

[40] L. Leydesdorff and I. Rafols, "Local emergence and global diffusion of research technologies: an exploration of patterns of network formation," Journal of the American Society for Information Science and Technology, vol. 62, no. 5, pp. 846860, 2011.

[41] J. Tanimoto, "Coevolutionary, coexisting learning and teaching agents model for prisoner's dilemma games enhancing cooperation with assortative heterogeneous networks," Physica A: Statistical Mechanics and its Applications, vol. 392, no. 13, pp. 2955-2964, 2013.
[42] R. S. Burt, Structure Holes: The Social of Competition, Harvard University Press, Boston, MA, USA, 1995.

[43] T. Kastelle and J. Steen, "Are small world networks always best for innovation?” Innovation, vol. 12, no. 1, pp. 75-87, 2010.

[44] D. Jansen, R. von Görtz, and R. Heidler, "Knowledge production and the structure of collaboration networks in two scientific fields," Scientometrics, vol. 83, no. 1, pp. 219-241, 2010.

[45] W. Tsai, "Knowledge transfer in interorganizational networks: effects of network position and absorptive capacity on business unit innovation and performance," Academy of Management Journal, vol. 44, no. 5, pp. 996-1004, 2001.

[46] M. de Laat, V. Lally, L. Lipponen, and R.-J. Simons, "Investigating patterns of interaction in networked learning and computer-supported collaborative learning: a role for social network analysis," International Journal of Computer-Supported Collaborative Learning, vol. 2, no. 1, pp. 87-103, 2007.

[47] W. Fang, S. Dai, and L. Wang, "Evolutionary model and simulation research of collaborative innovation network: a case study of artificial intelligence industry," Discrete Dynamics in Nature and Society, vol. 2018, Article ID 4371528, 13 pages, 2018.

[48] W. Fang and L. Xiao, "Simulation of knowledge transfer process model between universities: a perspective of cluster innovation network," Complexity, vol. 2018, Article ID 5983531, 13 pages, 2018.

[49] C. H. Liao, "How to improve research quality? Examining the impacts of collaboration intensity and member diversity in collaboration networks," Scientometrics, vol. 86, no. 3, pp. 747-761, 2011. 


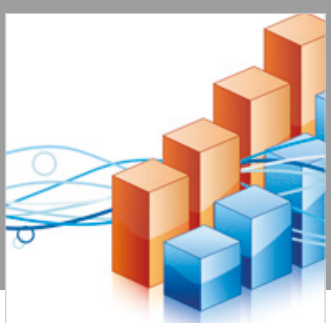

Advances in

Operations Research

\section{-n-m}
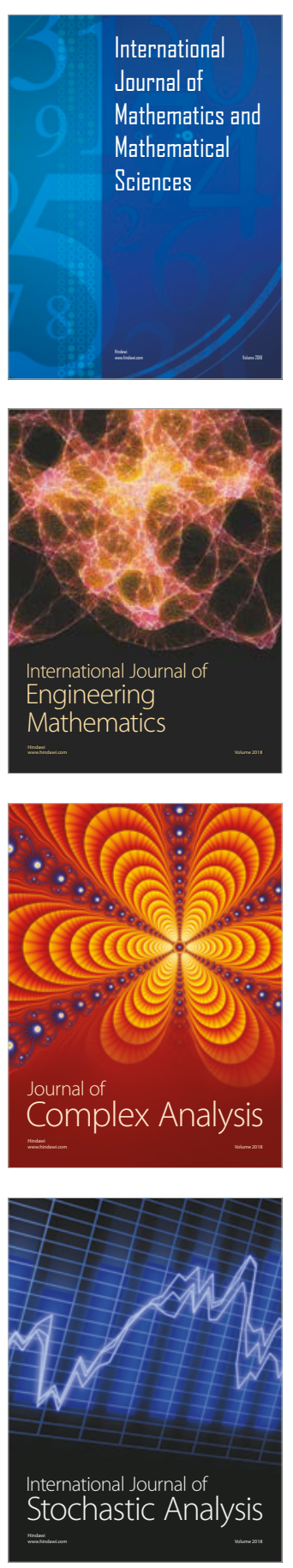
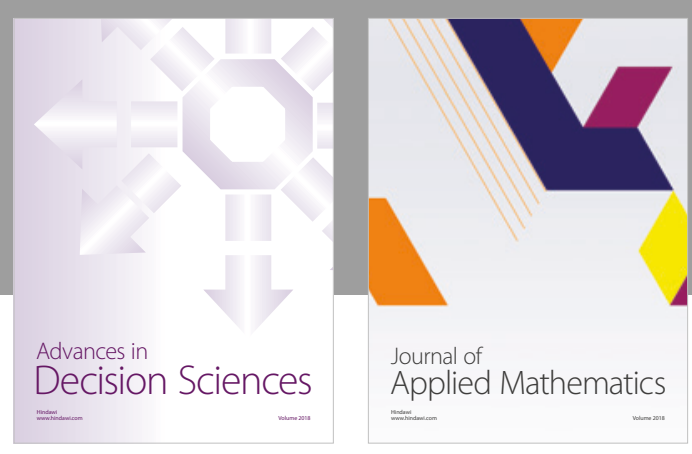

Journal of

Applied Mathematics
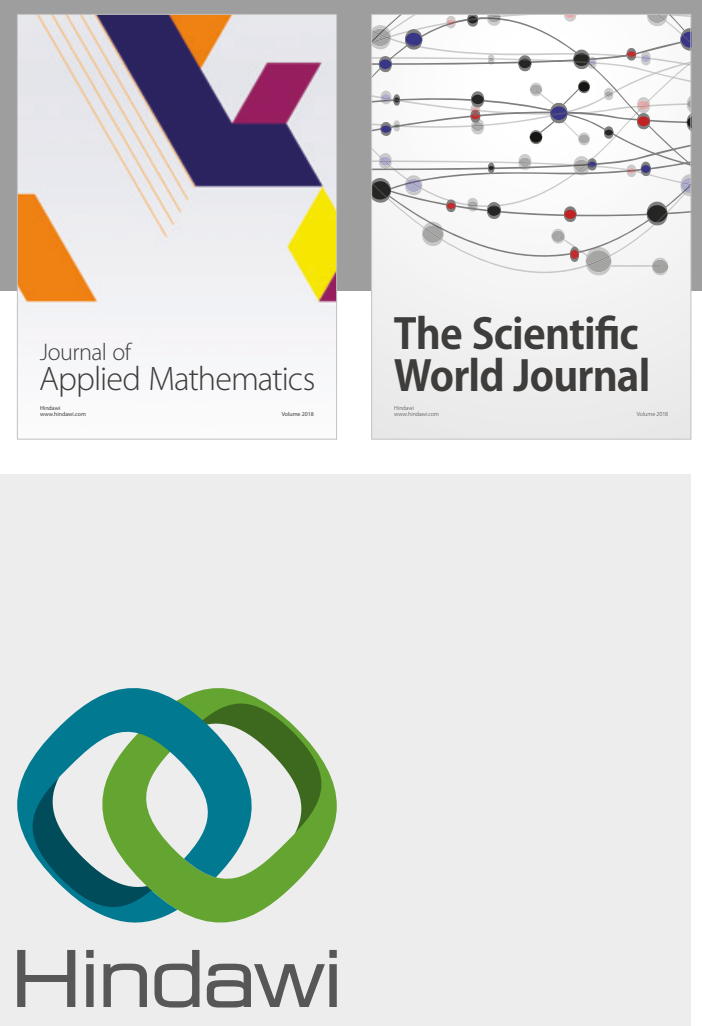

Submit your manuscripts at

www.hindawi.com

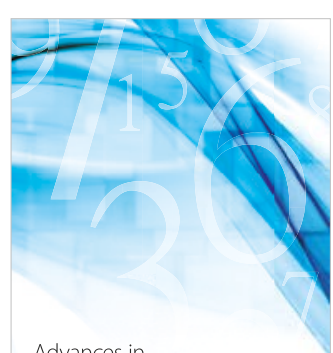

Advances in
Numerical Analysis
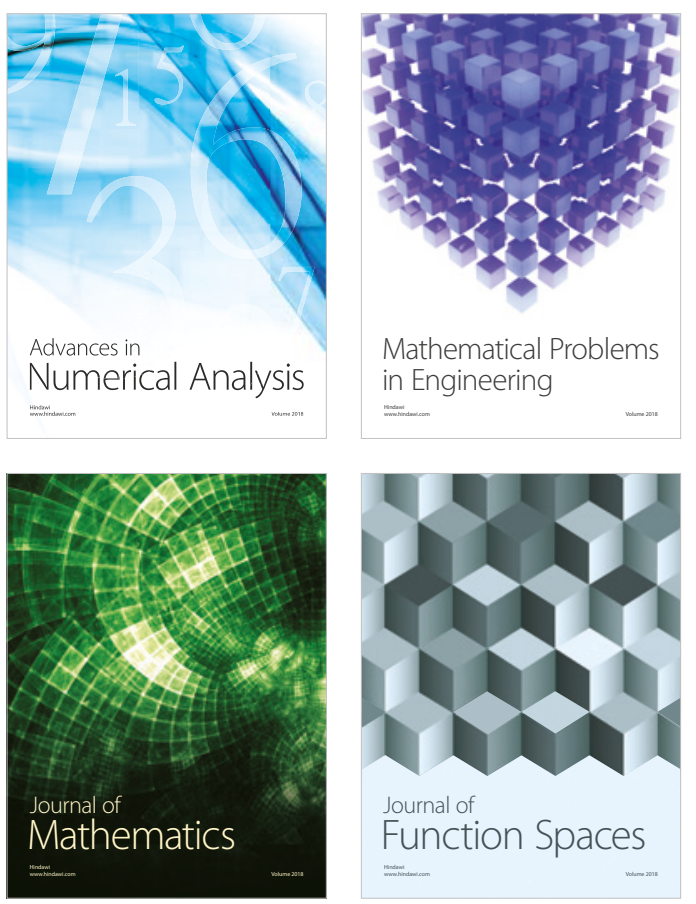

Mathematical Problems in Engineering

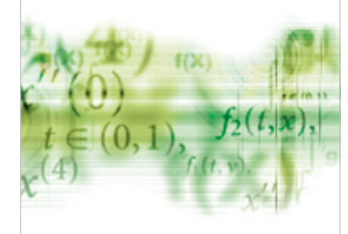

International Journal of

Differential Equations

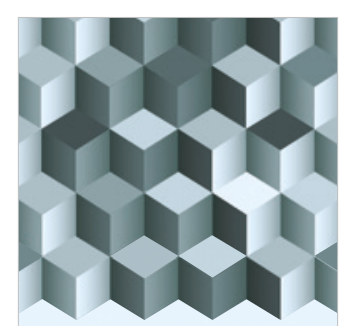

Journal of

Function Spaces
The Scientific

World Journal

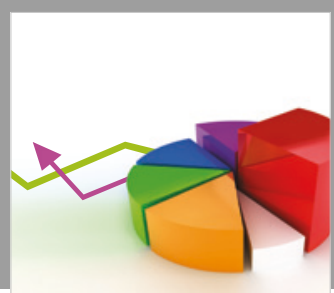

Journal of

Probability and Statistics
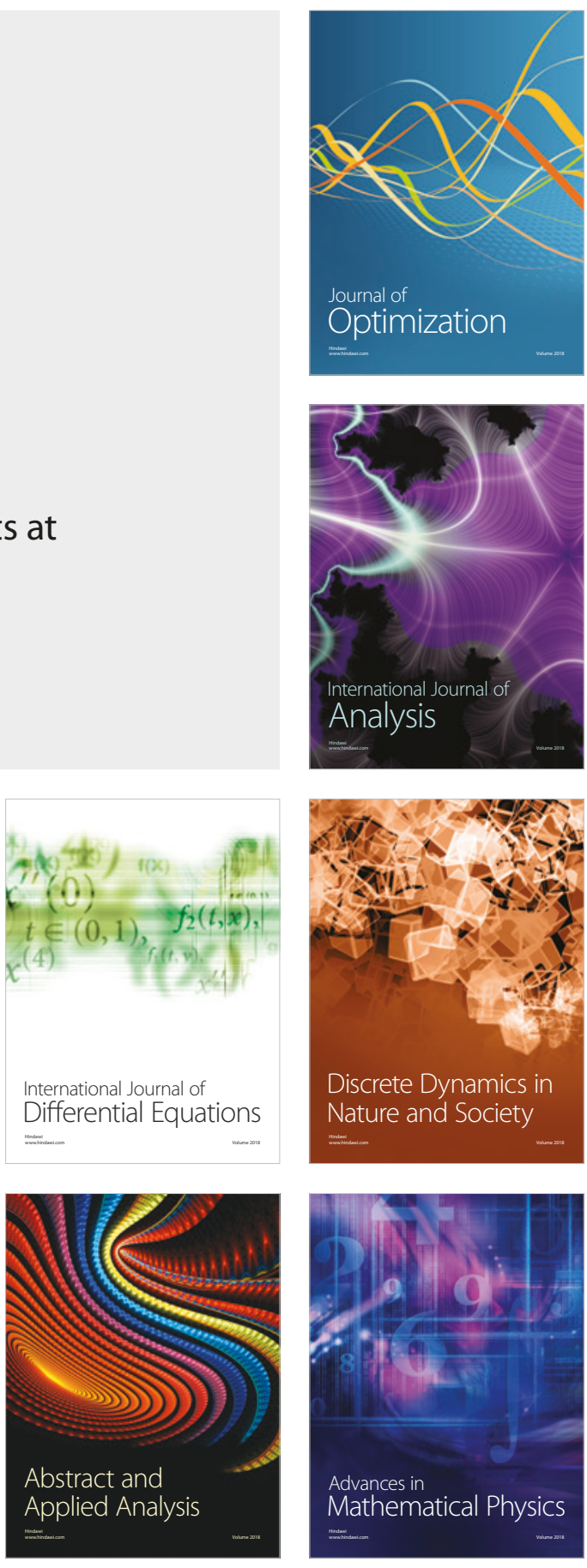